\title{
BROOKHGWEN
}

NATIONAL LABORATORY

BNL-112324-2016-JA

\section{DISTINCT EFFECTS OF ANTHROPOGENIC AEROSOLS ON THE EAST ASIAN SUMMER MONSOON BETWEEN MULTI- DECADAL STRONG AND WEAK MONSOON STAGES}

Xie, X., Wang, H., Liu, X., Li, J., Wang, Z., and Liu, Y.

Accepted for publication in

J. Geophys. Res. Atmos.

May 2106

\begin{abstract}
Environmental \& Climate Science Dept.
Brookhaven National Laboratory
\end{abstract}

\section{U.S. Department of Energy DOE Office of Science}

Notice: This manuscript has been authored by employees of Brookhaven Science Associates, LLC under Contract No. DE-SC0012704 with the U.S. Department of Energy. The publisher by accepting the manuscript for publication acknowledges that the United States Government retains a non-exclusive, paid-up, irrevocable, world-wide license to publish or reproduce the published form of this manuscript, or allow others to do so, for United States Government purposes. 


\section{DISCLAIMER}

This report was prepared as an account of work sponsored by an agency of the United States Government. Neither the United States Government nor any agency thereof, nor any of their employees, nor any of their contractors, subcontractors, or their employees, makes any warranty, express or implied, or assumes any legal liability or responsibility for the accuracy, completeness, or any third party's use or the results of such use of any information, apparatus, product, or process disclosed, or represents that its use would not infringe privately owned rights. Reference herein to any specific commercial product, process, or service by trade name, trademark, manufacturer, or otherwise, does not necessarily constitute or imply its endorsement, recommendation, or favoring by the United States Government or any agency thereof or its contractors or subcontractors. The views and opinions of authors expressed herein do not necessarily state or reflect those of the United States Government or any agency thereof. 


\section{Distinct effects of anthropogenic aerosols on the East Asian summer monsoon between multi-decadal strong and weak monsoon stages}

Xiaoning Xie ${ }^{1}$, Hongli Wang ${ }^{2}$, Xiaodong Liu ${ }^{1,3}$, Jiandong $\mathrm{Li}^{4}$, Zhaosheng

Wang ${ }^{1}$, and Yangang $\mathrm{Liu}^{5}$

${ }^{1}$ SKLLQG, Institute of Earth Environment, Chinese Academy of Sciences,

Xi'an, China

${ }^{2}$ Shaanxi Radio \& TV University, Xi'an, China

${ }^{3}$ Department of Environmental Science and Technology, School of Human

Settlements and Civil Engineering, Xi'an Jiaotong University, Xi'an, China

${ }^{4}$ LASG, Institute of Atmospheric Physics, Chinese Academy of Sciences,

Beijing, China

${ }^{5}$ Atmospheric Sciences Division, Brookhaven National Laboratory, Upton, New York, USA

Xiaoning Xie, Institute of Earth Environment, Chinese Academy of Sciences, No. 97 Yanxiang Road, Xi'an 710061, Shaanxi, China (xnxie@ieecas.cn) 


\section{Abstract.}

Because industrial emissions of anthropogenic aerosols over East Asia have greatly increased in recent decades, the interactions between atmospheric aerosols and the East Asian summer monsoon (EASM) have attracted enormous attention. To further understand the aerosol-EASM interaction, we investigate the impacts of anthropogenic aerosols on the EASM during the multi-decadal strong (1950-1977) and weak (1978-2000) EASM stages using the Community Atmospheric Model 5.1 (CAM5.1). Numerical experiments are conducted for the whole period, including the two different EASM stages, with present day (PD, year 2000) and pre-industrial (PI, year 1850) aerosol emissions, as well as the observed time-varying aerosol emissions. A comparison of the results from PD and PI shows that, with the increase in anthropogenic aerosols, the large-scale EASM intensity is weakened to a greater degree $(-9.8 \%)$ during the weak EASM stage compared with the strong EASM stage $(-4.4 \%)$. The increased anthropogenic aerosols also result in a significant reduction in precipitation over North China during the weak EASM stage, as opposed to a statistically insignificant change during the strong EASM stage. Because of greater aerosol loading and the larger sensitivity of the climate system during weak EASM stages, the aerosol effects are more significant during these EASM stages. These results suggest that anthropogenic aerosols from the same aerosol emissions have distinct effects on the EASM and the associated precipitation between the multi-decadal weak and strong EASM stages. 


\section{Key Points}

- Strong and weak EASM stages existed during 1950-2000

- The EASM can be weakened by aerosols with different magnitudes during strong and weak stages

- Increased aerosols result in a significant reduction in precipitation over North China during weak EASM stages 


\section{Introduction}

In recent decades, industrial emissions of aerosols over East Asia have greatly increased in association with rapid economic growth and industrialization [Nakajima et al., 2007; Zhang et al., 2012]. Interactions between atmospheric aerosols and the East Asian monsoon have garnered attention in the form of observational [Lau et al., 2008; Li et al., 2011; Liu et al., 2011a] and numerical [Menon et al, 2002; Zhu et al., 2012b] studies because of the persistent concern over environmental and climate problems, such as worsening air quality and increasing drought and flood disasters across East Asia.

It is well known that atmospheric aerosols have a direct impact on the local and global radiation balance by scattering and absorbing solar and infrared radiation in the atmosphere. Atmospheric aerosols, serving as cloud condensation nuclei (CCN) or ice nuclei (IN), can indirectly affect cloud albedo [Twomey, 1977], as well as precipitation processes

and cloud lifetime [Albrecht, 1989; Ramanathan et al., 2001]. With increased aerosol loading over Asia in recent decades, the climatic effects of atmospheric aerosols on Asian summer monsoon systems and regional precipitation have been of increasing research interest [Lau et al., 2008]. There is evidence that aerosol-induced circulation changes have affected rainfall in South Asia [Meehl et al., 2008; Bollasina et al., 2011]. For East Asia, a number of studies have reported that the abundant aerosols can affect the atmospheric circulation and precipitation of the East Asian summer monsoon (EASM) in global or regional climate models. For example, Menon et al. [2002] found that increased rainfall in the middle, and lower reaches of the Yangtze River and droughts in North China might result from increased black carbon aerosols. Liu et al. [2011b] explored the aerosol effects 
on the EASM using the CAM3.5 model and found a prominent rainfall decline over eastern China and weakening EASM due to the effect of anthropogenic aerosols. Similar results were also reported by Jiang et al. [2013] for the CAM5 model, Wang et al. [2015a] for ten CMIP5 model results with prescribed SST, and Wang et al. [2015b] for an online coupled regional climate-chemistry model, confirming the notion of a weakened EASM, as well as decreased precipitation in eastern China, in response to an increased amount of anthropogenic aerosols. Based on simulations of coupled ocean-atmosphere models, Song et al. [2014] also noted that the aerosol forcing plays a primary role in the EASM weakening in comparison with natural forcing and greenhouse gas forcing during 1958-2001. These studies have all shown that anthropogenic aerosols can weaken the EASM and change the associated summer precipitation over eastern China.

The EASM is known to exhibit inter-decadal variation with strong and weak stages that are associated with distinct climatic characteristics. A transition from strong to weak EASM occurred in the late 1970s; since then the EASM has been characterized by weakening of the $850 \mathrm{hPa}$ southwesterly winds, a southward shift of the $200 \mathrm{hPa}$ jet stream, and an increase in the sea-level pressure over East Asia, as well as South China flood and North China drought [e.g., Hu, 1997; Wang, 2001; Gong and Ho, 2002; Wang and Ding, 2006; Zhou et al., 2009]. Several mechanisms for the EASM weakening in the late 1970s have been proposed, including the change of sea surface temperature [Hu, 1997; Gong and Ho, 2002; Zhou et al., 2009], global warming [Zhu et al., 2012a], aerosol forcing (Menon et al. 2002; Liu et al. 2011b), and other factors [Xiao and Li, 2007; Ding et al., 2008; Feng et al., 2011]. 
Although the potential effects of increased aerosols on the EASM and the associated precipitation have been investigated with different types of models [e.g., Liu et al., 2011b; Jiang et al., 2013; Song et al., 2014; Wang et al., 2015a; Wang et al., 2015b], previous studies have not compared and examined the differences in aerosol effects between strong and weak EASM stages. Hence, one question remains unanswered: Are there any differences in the effects of anthropogenic aerosols on the EASM and the associated clouds and precipitation between the multi-decadal weak and strong EASM stages? Addressing this question is the primary purpose of this paper, which can advance a deeper understanding of aerosol-EASM interaction.

The organization of the rest of the paper is as follows. Section 2 describes the key features of the CAM5.1 model and the simulation setups. In Section 3, the model performance is also evaluated against observations and reanalysis, with a focus on the model ability to simulate the strong and weak EASM stages during 1950-2000. Furthermore, it also presents the results of aerosol effects on EASM, precipitation, cloud properties, and radiative flux during the strong and weak EASM stages, and examines the corresponding differences between the two different EASM stages. The discussion and conclusions are summarized in Sections 4 and 5, respectively.

\section{Model Description and Experiment Setup}

This study uses version 5.1 of the Community Atmosphere Model (CAM5.1), which is the atmospheric component of the Community Earth System Model (CESM 1.0.3) [Neale et al., 2010]. We ran CAM5.1 with the finite-volume dynamical core with a horizontal resolution of $1.9^{\circ}$ at latitude and $2.5^{\circ}$ at longitude and with 30 levels from the surface to 2 hPa. All the CAM5.1 simulations were run for the years 1950-2000 and constrained 
with the observed SST, sea ice concentrations, and atmospheric forcings (greenhouse gases (GHGs), tropospheric and stratospheric ozone, and solar irradiance) during this period. The SST and sea ice extent were from a merged version of the HadISST [Rayner et al., 2003] and the optimum interpolation SST data sets described by Hurrell et al. [2008]. A complete set of physics packages was selected to allow for effective investigation of the direct, semi-direct and indirect effects of aerosols [Ghan et al., 2012; Ghan 2013]. Briefly, a 3-mode modal aerosol scheme (MAM3) was implemented in the model to simulate internal mixtures of sulfate, primary organic matter (POM), black carbon (BC), dust and sea-salt [Liu et al., 2012b]. This MAM3 scheme has been shown to capture the seasonal and spatial variations in aerosol optical depth (AOD) over East Asia when compared with the satellite observations [Liu et al., 2012b], although the modeled AOD is lower than observations at urban sites. The CAM5.1 model contains a detailed treatment of stratiform cloud microphysics processes and aerosol indirect effects by coupling the MAM3 scheme to a two-moment bulk cloud microphysics scheme [Morrison and Gettelman, 2008] with comprehensive descriptions of droplet activation and ice nucleation of cloud droplets [Gettelman et al., 2010]. The shortwave and longwave radiative transfers are based on the Rapid Radiative Transfer Model for GCMs, known as RRTMG [Iacono et al., 2008].

A total of three different experiments are carried out for the years 1950-2000, with the sole difference being the treatment of aerosols and precursor gas emissions. The control (CTL) experiment uses the observed time-varying aerosol and precursor gas emission dataset from the IPCC AR5 aerosol emission dataset [Lamarque et al., 2010]. In the other two experiments, the aerosol and precursor gas emissions are fixed for the whole simulation period: the present day (PD) experiment uses the emissions of 2000 and the 
pre-industrial (PI) experiment uses the emissions of 1850. The key characteristics of the three numerical experiments are summarized in Table 1 for convenience. The results of the CTL experiment are used to evaluate the model performance with the observational data. Differences between the PD and PI experiments are used to gauge the effect of the anthropogenic aerosols. According to Ding et al. [2008], the EASM experienced a strong EASM stage from 1950 to 1977 and a weak EASM stage from 1978 to 2000. The simulations of the three experiments during the two EASM stages are used to examine the differences between the strong and weak ESAM stages.

\section{Model Results}

\subsection{Evaluation of the CAM5.1 Model}

It is well known that the southerly monsoonal wind in the lower troposphere is dominant over eastern China in summer, which brings water vapor to this region from the Pacific and Indian Oceans, and is directly related to summer precipitation over eastern China. Additionally, the aerosol distribution in seasonal or annual means is mainly affected by the low level meridional circulation over eastern China (Liu et al., 2011a; Zhu et al., 2012b). Hence, we use the averaged summer meridional wind at $850 \mathrm{hPa}$ over eastern China $\left(105^{\circ} \mathrm{E}-122.5^{\circ} \mathrm{E}\right.$ and $\left.20^{\circ} \mathrm{N}-45^{\circ} \mathrm{N}\right)$ as an EASM index to directly measure the large-scale EASM intensity. The same or similar indices have been widely used to examine the modern and past changes in the East Asian monsoon [e.g., Wang et al., 2008; Jiang and Lang,

2010]. Figure 1a compares the time series of the normalized EASM index derived from the CTL experiment, the NCEP/NCAR and ERA-40 reanalyses. The results indicate that the CAM5.1 model poorly reproduces the interannual variation of the EASM compared with the NCEP/NCAR and ERA-40 reanalyses, especially in the weak EASM stage (with 
correlation coefficients of 0.39 and 0.15 for the whole period, 0.38 and 0.20 for the strong EASM stage, and -0.07 and -0.06 for the weak EASM stage, respectively). Additionally, it is emphasized that, compared to the interannual variation in the EASM, this model can better simulate the two different EASM stages in 1950-1977 (P1, strong) and 1978-2000 (P2, weak) (Figure 1b). Note that the model yields similar magnitudes of change from the strong to weak EASM stages compared with those based on the ERA-40 reanalysis (Figure 1d), but weaker magnitudes compared to the NCEP/NCAR reanalysis (Figure 1c).

Figure 2 further compares the summer mean 850 hPa winds of 1950-2000 (left panel) and the corresponding difference between the weak (1978-2000) and strong EASM stages (1950-1977) (right panel) from CAM5.1 (upper panel), the NCEP/NCAR reanalysis (middle panel), and the ERA-40 reanalysis (lower panel). Figures 2a, c and e show that CAM5.1 and the two reanalyses all exhibit southerly monsoonal wind over eastern China. Figures $2 \mathrm{~b}$, d and f show that the differences between the strong and weak EASM stages in CAM5.1 and the two reanalyses all exhibit an anomalous northerly wind, suggesting that the southerly monsoonal wind in eastern China is weakened from the strong to weak EASM stages. The model yields weaker anomalous northerly winds over eastern China between the weak and strong EASM stages compared to these two reanalysis. Additionally, the model also displays a low-level anomalous anticyclonic circulation over the western North Pacific, whereas this is not evident in the NCEP/NCAR and ERA-40 reanalyses. It is noteworthy that the NCEP/NCAR reanalysis displays a much stronger anomalous northerly wind between the two EASM stages compared with the ERA-40 
reanalysis, likely because of its questionable data quality before the 1970s over the region [Wu et al., 2005].

Our analysis also shows that the CAM5.1 model reasonably reproduces the land-sea difference in sea-level pressure, the distributions of zonal winds at the $200 \mathrm{hPa}$ level, and the southerly winds bringing moisture from the oceans at the $850 \mathrm{hPa}$ level for June-August (summer) for the climatological mean of 1950-2000 (Figure S1). However, the sea-level pressure over the western Pacific shows that the intensity of the western Pacific subtropical high (WPSH) in the middle and lower troposphere is stronger and that it shifts northward in comparison with the NCEP/NCAR and ERA-40 reanalyses, which is similar to different versions of the CAM model [Chen et al., 2010; Li et al., 2010]. Hence, our results suggest that the CAM5.1 model can capture the main climate features of the EASM circulation, except the intensity and position of the WPSH as revealed by the reanalyses. For the simulated precipitation, the CAM5.1 model can capture the heavy rainfall over India and the rainfall decrease from the southeast coast to the northwest inland areas of East Asia (Figure S2). The model overestimates the precipitation over North China and underestimates the precipitation over South China due to the bias of the intensity and position of the WPSH [Chen et al., 2010; Li et al., 2010]. The results are similar to previous studies using different versions of the CAM model [Chen et al., 2010; Liu et al., 2011b; Jiang et al., 2013]. Additionally, it is noted that the CAM5.1 model cannot reproduce the spatial pattern of South China flood and North China drought between the weak and strong EASM stages in the observations, demonstrating that the simulation of precipitation over East Asia (especially eastern China) still requires improvement, similar to the earlier version of the CAM model [Li et al., 2010]. 
The above results of comparison between the model, the NCEP/NCAR and ERA-40 reanalyses indicate that despite the detailed differences, the CAM5.1 model captures the main EASM features and can be used to examine the various aerosol effects and their differences between strong and weak EASM stages. The disagreement may be related to the fact that the CAM5.1 model underestimates AOD over Asia by more than $50 \%$ compared with satellite observations [Liu et al. 2012b]. The AOD underestimation is probably due to the underestimation of anthropogenic aerosol emissions after the end of the 1970s. It is expected that more accurate anthropogenic emissions may increase AOD after the 1970s, weaken the EASM more, and enhance the magnitude of change from strong to weak EASM stages in the CTL experiment.

\subsection{Increase in Anthropogenic Aerosols}

Figure 3 shows the difference in AOD at $550 \mathrm{~nm}$ wavelength between PD and PI in summer during the strong and weak EASM stages. This AOD difference can be used as a measure of the anthropogenic AOD, i.e., AOD related to anthropogenic emissions. Here, eastern China is defined as the region from $105^{\circ} \mathrm{E}$ to $122.5^{\circ} \mathrm{E}$ and from $20^{\circ} \mathrm{N}$ to $45^{\circ} \mathrm{N}$, with North China $\left(105^{\circ} \mathrm{E}-122.5^{\circ} \mathrm{E}\right.$ and $\left.33^{\circ} \mathrm{N}-45^{\circ} \mathrm{N}\right)$ being a sub-region of eastern China. It is evident that most anthropogenic AODs are greater than 0.06 over eastern China due to the large increases in emissions associated with the rapid economic development in recent decades. The anthropogenic AOD is even higher in North China (reaching 0.12 or higher). A comparison further shows that the anthropogenic AOD during the weak EASM stage is higher than that during the strong EASM stage, with the corresponding domain averages being 0.113 and 0.100 over eastern China and 0.137 and 0.113 over North China, respectively. Similarly, the total column burden of anthropogenic aerosols 
and the sulfate, BC and POM column burden are also higher during the weak EASM stage than that during the strong EASM stage over eastern China and over North China. The results are summarized in Table 2 for convenience. Our results suggest that for the same anthropogenic emissions, the AOD and the column burden of anthropogenic aerosols over eastern China (especially over North China) can be significantly higher in the weak EASM stage than in the strong EASM stage. The discrepancy in aerosol properties between the different EASM stages likely arises from the fact that the weak (strong) southerly wind during the weak (strong) ESAM stage reduces (enhances) aerosol northward transport, which redistributes aerosols over eastern China, reach outside this region and causes aerosols to converge (diverge) over eastern China in Figure S3. The different aerosol properties are also expected to cause differences in various aerosol effects

\subsection{Aerosol-Induced EASM Weakening}

As noted above, the southerly monsoonal wind in the lower troposphere dominates eastern China in the summer, bringing moisture to this region from the Pacific and Indian Oceans. Hence, we use the averaged summer meridional wind at $850 \mathrm{hPa}$ within eastern China $\left(105^{\circ} \mathrm{E}-122.5^{\circ} \mathrm{E}\right.$ and $\left.20^{\circ} \mathrm{N}-45^{\circ} \mathrm{N}\right)$ during the strong and weak EASM stages to directly measure the large-scale EASM intensity. Figure 4 compares the difference in the summer $850 \mathrm{hPa}$ wind field between PD and PI during the strong (a) and weak (b) EASM stages. Here, the red shaded areas with green dots represent the grid points where the changes pass the two-tailed t-test at the $5 \%$ significance level. Three points are evident from this figure. First, the southerly winds over eastern China in the PD simulation are weaker than those in the PI simulation during the two different EASM 
stages, suggesting EASM weakening caused by anthropogenic aerosols. Second, it can be seen that the large-scale EASM intensity is weakened more significantly $\left(-0.37 \mathrm{~m} \mathrm{~s}^{-1}\right)$ by anthropogenic aerosols during the weak EASM stage than that $\left(-0.17 \mathrm{~m} \mathrm{~s}^{-1}\right)$ during the strong EASM stage (Table 3). The percentage change in the large-scale EASM intensity also shows a larger reducing magnitude (-9.8\%) during the weak EASM stage and a smaller reducing magnitude $(-4.4 \%)$ during the strong EASM stage. Finally, the area of the aerosol-weakened monsoon that passes the two-tailed t-test at the $5 \%$ significance level is much larger (by a factor of 2) in the weak EASM stage than in the strong EASM

Figure 5 compares the PD-PI differences in the surface temperature and sea-level pressure during the strong and weak EASM stages. It is evident that anthropogenic aerosols result in a decrease in surface temperature and an increase in sea-level pressure over eastern China during both EASM stages. The decrease in surface temperature and increase in sea-level pressure over continental eastern China further lead to a reduction in the land-sea thermal and pressure gradients, suppressing water vapor transport from the ocean into eastern China and weakening the EASM. These results are consistent with the findings of Liu et al. [2011b], Jiang et al. [2013], Wang et al. [2015a] and Wang et al.

Also evident in Figure 5 are the striking differences in the aerosol-induced changes in surface temperature and sea-level pressure between the weak and strong EASM stages. During the weak EASM stage, the changes in surface temperature and sea-level pressure are more significant compared to those during the strong EASM stage. This can be seen more clearly in Table 6, which shows that the average surface temperature decreases by 
$-0.44^{\circ} \mathrm{C}$ during the weak EASM stage and by $-0.39^{\circ} \mathrm{C}$ during the strong EASM stage; the

average sea-level pressure increases by $0.30 \mathrm{hPa}$ during the weak EASM stage and by 0.16 hPa during the strong EASM stage. Furthermore, the locations of changes are different: during the weak EASM stage, the changes are centered over eastern China whereas the corresponding changes are located over the north part of North China during the strong EASM stage. These changes and their differences between the two EASM stages are likely related to the changes in the radiative flux caused by aerosols (see Subsection 3.5). These results collectively suggest that for the same increase in anthropogenic aerosol emissions, the EASM is weakened more when it is weaker. Two mechanisms may be responsible for the distinct effects of anthropogenic aerosols on the EASM between the strong and weak EASM stages. First, in the weak EASM stage, higher anthropogenic AOD can lead to lower surface temperatures and higher sea-level pressures through aerosol direct and indirect radiative forcing, which further weakens the EASM. These results can also be seen in changes in cloud properties and radiative flux by anthropogenic aerosols discussed in Subsection 3.5. Second, as will be discussed later in Subsection 3.6, during the weak EASM stage, the climate system is more sensitive to external forcings; hence, the same forcing of anthropogenic aerosols can result in a larger reduction in the large-scale EASM

\subsection{Aerosol-Induced Precipitation Change}

Figure 6 shows the changes in total precipitation (including convective and large-scale precipitation) caused by anthropogenic aerosols for the two EASM stages. It is interesting to note that precipitation is suppressed by the anthropogenic aerosols over South China, Southwest China and the Indo-China Peninsula, whereas precipitation is enhanced over 
the South China Sea and the western Pacific Ocean during both the weak and strong ESAM stages. Although these general patterns of change in precipitation between PD and PI are very similar for these two different EASM stages, there are distinct differences between the weak and strong EASM stages in North China. On average, the precipitation during the weak EASM stage is reduced significantly by a magnitude of $-0.62 \mathrm{~mm}$ day $^{-1}$ (or $-11.1 \%$ ) whereas the precipitation in the strong EASM stage is insignificantly enhanced by anthropogenic aerosols (by $0.10 \mathrm{~mm} \mathrm{day}^{-1}$ or $1.9 \%$ ) (Table 3 ).

To explore the possible mechanisms underlying the difference in precipitation changes in North China, we examine the change in the summer water vapor transport and specific humidity between PD and PI in the different EASM stages (Figure 7). It is clear that the water vapor flux is reduced in North China due to the aerosol-induced EASM weakening during both the weak and strong EASM stages. During the weak EASM stage, the water vapor flux is more significantly reduced by anthropogenic aerosols in North China (Figure 7b) compared to the strong EASM stage (Figure 7a), leading to greater reduction in specific humidity (Figure 7d). Additionally, we also observe that the upward vertical velocity is substantially reduced by increased aerosol loading in the weak EASM stage (Figure 8b). In the strong EASM stage, the aerosol-induced atmosphere circulation change produces an anomalous upward vertical velocity that forms more clouds and precipitation over North China (Figure 8a). Table 4 further provides the regionally averaged values of water vapor flux and flux convergence, specific humidity, total precipitable water and vertical velocity for PD, PI and their differences between the strong and weak EASM stages. The average changes in the $850 \mathrm{hPa}$ water vapor flux $\left(-3.18 \mathrm{~g}(\mathrm{hPa} \mathrm{m} \mathrm{s})^{-1}\right)$, water vapor flux convergence $\left(0.42 \times 10^{-5} \mathrm{~g}\left(\mathrm{hPa} \mathrm{m} \mathrm{m}^{2} \mathrm{~s}\right)^{-1}\right)$, specific humidity $(-0.37 \mathrm{~g}$ 
$\left.\mathrm{kg}^{-1}\right)$, precipitation water $\left(-1.13 \mathrm{~kg} \mathrm{~m}^{-2}\right)$, and vertical velocity $\left(0.0033 \mathrm{~Pa} \mathrm{~s}^{-1}\right)$ during the weak EASM stage are much larger than the corresponding values during the strong EASM stage. Additionally, a larger aerosol burden that cools the surface and stabilizes the boundary layer is a possible reason for reduced precipitation in the weak EASM stage (Liu et al., 2011b).

It is noteworthy that the CAM5.1 model does not consider the aerosol indirect effect on convective clouds. In view of the importance of convective clouds in precipitation (see a recent review by Tao et al., 2012), caution is needed in the interpretation of these results.

\subsection{Aerosol-Induced Changes in Cloud Properties and Radiative Flux}

Table 5 summarizes the key cloud properties for PD, PI and their differences over eastern China, including the column cloud droplet number concentration, liquid water path, $850 \mathrm{hPa}$ cloud droplet effective radius, and low cloud cover. With the increase in anthropogenic aerosols, the cloud droplet number concentration and liquid water path are appreciably increased by $2.78 \times 10^{6} \mathrm{~cm}^{-2}$ and $2.63 \times 10^{6} \mathrm{~cm}^{-2}$ and by $23.00 \mathrm{~g} \mathrm{~m}^{-2}$ and 18.75 $\mathrm{g} \mathrm{m}^{-2}$ in the strong and weak EASM stages, respectively. In contrast, the cloud droplet effective radius is decreased by $-1.23 \mu \mathrm{m}$ and $-1.29 \mu \mathrm{m}$ in the strong and weak EASM stages, respectively. Additionally, the low cloud cover is increased by $1.52 \%$ and $0.54 \%$ due to anthropogenic aerosols for the strong and weak monsoon stages, respectively. These changes are consistent with the notion that additional activation of aerosols leads to the formation of more cloud droplets with smaller sizes and hinders the conversion of cloud droplets to raindrops, resulting in much greater liquid water path values and increased cloud cover (Xie et al., 2013). The differences in the cloud properties between the two EASM stages are worth noting. The larger decrease in cloud droplet effective radius 
during the weak EASM stage conforms to the fact of larger AOD and aerosol burden. However, the change in droplet concentration, liquid water path, and low cloud fraction are larger in the strong EASM stage than that in the weak EASM stage. This seemingly counter-intuitive phenomenon is likely related to the concurrent changes in circulation that generate anomalous upward vertical velocity and form more clouds over North China in the strong EASM stage.

The increases in liquid water path and low cloud fraction and the decrease in cloud droplet effective radius conspire to increase the cloud radiative forcing, thereby altering the local and global radiation balance. Figure 9 shows the differences in the surface and TOA aerosol total radiative flux (including aerosol direct radiative forcing (ADF) and aerosol indirect radiative forcing (AIF)) for the two EASM stages. It can be seen that the decreases in the radiative flux are more significant at both the surface and the TOA in the weak EASM stage. The aerosol total radiative forcing is mainly located over eastern China in the weak EASM stage, whereas it is concentrated over North China in the strong EASM stage because of the larger AIF over North China in strong EASM stage (Figures S4 and S5). The discrepancy between the two EASM stages in the spatial distribution of aerosol total radiative forcing may be the reason for the similar behavior of surface temperature and sea-level pressure. A higher anthropogenic AOD leads to greater aerosol radiative forcing, which further results in a lower surface temperature and higher sea-level pressure over eastern China.

Table 6 provides the shortwave and longwave radiative fluxes at the surface. One can see that the shortwave flux is reduced significantly by anthropogenic aerosols whereas the longwave flux is increased only slightly. Note that the aerosol-induced shortwave flux 
dominated the changes in the radiative fluxes for both clear-sky and cloudy-sky radiative fluxes (which can be directly derived from the difference between all-sky and clear-sky radiative fluxes in the model). It is interesting to note that the magnitude of AIF is slightly smaller than that of ADF at the surface whereas the magnitude of AIF is much larger than that of ADF at the TOA (Table 8). These results highlight the non-negligibility of AIF compared with ADF.

Notably, the aerosol direct radiative forcing is herein simply defined as the clear-sky radiative flux with and without anthropogenic aerosols (the clear-sky radiative flux is calculated as a diagnostic with clouds neglected), whereas the aerosol indirect radiative forcing is described as the change in the cloud radiative forcing with and without anthropogenic aerosols (reviewed by Ghan 2013). Here, the aerosol indirect radiative forcing includes the first and the second indirect effects, as well as the semi-direct effect. Additionally, Ghan [2013] also noted that this estimation about ADF and AIF is biased regardless of surface albedo forcing, which can solve this problem by two additional diagnostic calculations.

\subsection{Sensitivity study}

In addition to aerosol loading itself, another important question related to the resultant changes is the sensitivity to the given the aerosol perturbation defined as the differences between PD and PI simulations divided by the corresponding difference in AOD or the anthropogenic AOD: (PD-PI)/ $\triangle \mathrm{AOD}$. A positive (negative) value of the sensitivity indicates that the corresponding variable increases (decreases) with increasing anthropogenic aerosols. Table 9 compares the sensitivities for ADF, AIF, aerosol total radiative forcing $(\mathrm{ADF}+\mathrm{AIF})$ at the surface and at the TOA, surface temperature, sea-level pressure over eastern China, the large-scale EASM intensity, and the total precipitation over North 
China in the different EASM stages. It is evident that ADFs at both the surface and TOA, sea-level pressure, large circulation intensity, and total precipitation are more sensitive to anthropogenic aerosols during the weak EASM stage, whereas AIF and aerosol total radiative forcing are more sensitive to aerosol perturbation during the strong EASM stage. The sensitivity of surface temperature is similar in both EASM stages. The larger AIF sensitivity in the strong EASM stage may be due to the aerosol-induced anomalous upward vertical velocity that forms more clouds, which is the reason for a larger sensitivity of the aerosol total forcing. The sensitivity of the total precipitation over North China is more interesting: it is positive during the strong EASM phase but negative during the weak EASM stage. The difference in the magnitude of precipitation sensitivity further indicates that the precipitation reduction in the weak EASM stage $(-5.5)$ is more sensitive to increasing aerosol loading than the precipitation increase in the strong EASM stage. Hence, the same forcing of anthropogenic aerosols can result in more significant reductions in the EASM and the associated summer precipitation in the weak EASM stage.

\section{Further Discussion}

The proceeding results collectively suggest three main reasons for the remarkable differences between the multi-decadal strong and weak EASM stages in terms of the effects of anthropogenic aerosols on EASM and associated climatic variables, such as precipitation, as illustrated in the schematic diagram in Figure 10. Briefly, for the same anthropogenic aerosol and gas precursor emissions, the AOD is smaller during the strong EASM stage over eastern China (Figure 3a) due to greater northward transport of the aerosols induced by strong southerly winds. The smaller anthropogenic AOD results in a smaller decrease in the surface temperature, a smaller increase in the sea-level pressure over eastern China 
(Figures 5a and 5c), and weaker changes in the EASM (Figure 4a) and summer precipitation (Figure 6a) over North China, in combination with the lower sensitivities in the strong EASM stage. During the weak EASM stage, the same increase in anthropogenic emissions leads to a much larger increase in AOD due to less northward transport of the aerosols (Figure 3b). This in turn leads to a larger decrease in surface temperatures and increase in sea-level pressure over eastern China (Figure 5b and 5d). In combination with larger sensitivity in the weak EASM stage, this greater variation can result in more significant reduction in the EASM (Figure 4b) and in summer precipitation (Figure 6b) over North China. Furthermore, because a weak EASM tends to increase the quantity of aerosols for the same emissions, the stronger aerosol effect during the weak EASM stage is likely related to some positive feedbacks between increased aerosols, weaker wind, and

\section{Concluding Remarks}

This study first evaluates the CAM5.1 model against the NCEP/NCAR and ERA-40 reanalyses in terms of the ability to simulate the EASM and its transition from strong to weak EASM stages. We then perform numerical experiments to investigate the impacts of anthropogenic aerosols on EASM and the associated climate changes, such as precipitation, cloud and radiative properties during the multi-decadal strong (1950-1977) and weak (1978-2000) EASM stages using CAM5.1. The numerical experiments are conducted for the whole period, including the two different EASM stages, with present day (PD, year 2000) and pre-industrial (PI, year 1850) aerosol emissions, as well as the observed time-varying aerosol emissions. A comparison of the results from PD and PI shows that, with the increase in anthropogenic aerosols, the large-scale EASM intensity is weak- 
ened to a greater degree $(-9.8 \%)$ during the weak EASM stage than during the strong EASM stage $(-4.4 \%)$. The increased anthropogenic aerosols also result in a significant reduction in precipitation over North China during the weak EASM stage, as opposed to a statistically insignificant change during the strong EASM stage. Because of the greater aerosol loading and greater sensitivity of the climate system during weak EASM stages, the aerosol effects are more significant during these EASM stages. Our results suggest that the anthropogenic aerosols under the same aerosol emissions have distinct effects on the EASM and the associated precipitation between the strong and weak EASM stages.

The following discussions are noteworthy. First, the aerosol indirect effect is only considered in large-scale stratiform clouds and precipitation in CAM5.1, and the aerosol-cloud interactions in convective clouds are ignored. As we know, the aerosol effects on convection clouds are very important to cloud radiative forcing and precipitation, which is dependent on many factors e.g., atmospheric relative humidity, vertical wind shear, and convective available potential energy (CAPE) (reviewed by Tao et al., 2012). Hence, a more complete investigation with a climate model that considers both aerosol effects on stratiform and convective clouds is desirable. Second, Liu et al. [2012a] noted that the EASM might have strengthened since the 1990s or the 2000s, and this period may be another strong EASM stage. This needs to be further confirmed with more and longer observations in the future. If the strong EASM stage since the 1990s or the 2000s can be confirmed, we will further use this new strong EASM stage to check our results. Finally, although anthropogenic aerosols can weaken the EASM significantly, especially during the weak EASM stage, we do not believe that the increase of anthropogenic aerosols is the dominant factor driving EASM into the weak stage after the end of the 1970s. This 
can be seen from Figure S6, S7 and Table S1, which show that the low-level anomalous northerly winds between the strong and weak EASM stages can been seen in both PI and PD experiments and are similar to those in the CTL experiment. These results imply that anthropogenic aerosol forcing only plays a complementary role [Song et al., 2014]; other factors (e.g., the variability in sea surface temperatures) may play a dominant role in the EASM weakening after the end of the 1970s.

\section{Acknowledgements}

We thank three anonymous reviewers for their constructive comments and suggestions, which helped us improve the manuscript. The NCEP/NCAR reanalysis data and GPCP Version 2.2 data were provided by the NOAA/OAR/ESRL PSD, Boulder, Colorado, USA, from their website at http://www.esrl.noaa.gov/psd/, and the ERA40 reanalysis data were obtained from the European Centre (http://apps.ecmwf.int/datasets/) in our study. This work was jointly supported by the National Basic Research Program of China (2011CB403406), the National Natural Science Foundation of China (41290255, 41105071) and the CAS Strategic Priority Research Program (XDA05110101). Y. Liu is supported by the US Department of Energy's Atmospheric System Research (ASR) program.

\section{References}

Albrecht, B. A. (1989), Aerosols, cloud microphysics and fractional cloudiness, Science, $245,1227-1230$.

Bollasina, M. A., Y. Ming, and V. Ramaswamy (2011), Anthropogenic aerosols and the weakening of the South Asian summer monsoon, Science, 334(6055), 502-505, doi:10.1126/science.1204994. 
Chen, H., T. Zhou, R. B. Neale, X. Wu, and G. J. Zhang (2010), Performance of the new NCAR CAM3.5 model in East Asian summer monsoon simulations: Sensitivity to modifications of the convection scheme, J. Climate, 23, 3657-3675.

Ding, Y., Z. Wang, and Y. Sun (2008), Inter-decadal variation of the summer precipitation in East China and its association with decreasing Asian summer monsoon. Part I: Observed evidences, Int. J. Climatol., 28(9), 1139-1162.

Feng, R., J. Li, and J. Wang (2011), Regime Change of the Boreal Summer Hadley Circulation and Its Connection with the Tropical SST, J. Climate, 24, 3867-3877.

Gettelman, A., X. Liu, S. J. Ghan, H. Morrison, S. Park, A. J. Conley, S. A. Klein, J. Boyle, D. L. Mitchell, and J.-L. F. Li (2010), Global simulations of ice nucleation and ice supersaturation with an improved cloud scheme in the community atmosphere model, J. Geophys. Res., 115, D18216, doi:10.1029/2009JD013797.

Ghan, S. J., X. Liu, R. C. Easter, R. Zaveri, P. J. Rasch, J. H. Yoon, and B. Eaton (2012), Toward a minimal representation of aerosols in climate models: Comparative decomposition of aerosol direct, semidirect, and indirect radiative forcing, J. Climate, $25,6461-6476$.

Ghan, S. J. (2013), Technical note: Estimating aerosol effects on cloud radiative forcing, Atmos. Chem. Phys., 13, 9971-9974, doi:10.5194/acp-13-9971-2013.

Gong, D., and C. Ho (2002), Shift in the summer rainfall over the Yangtze River valley in the late 1970s, Geophys. Res. Lett., 29(10), 1436, doi:10.1029/2001GL014523.

Hu, Z. Z. (1997), Interdecadal variability of summer climate over east Asia and its association with $500 \mathrm{hPa}$ height and global sea surface temperature, J. Geophys. Res., 102, $19403-19412$. 
Hurrell, J., J. Hack , D. Shea, J. Caron, and J. Rosinski (2008), A new sea surface temperature and sea ice boundary data set for the Community Atmosphere Model, $J$. Climate, 21(19), 5145-5153. doi:10.1175/2008JCLI2292.1

Iacono, M. J., J. S. Delamere, E. J. Mlawer, M. W. Shephard, S. A. Clough, and W. D. Collins (2008), Radiative forcing by long-lived greenhouse gases: Calculations with the AER radiative transfer models, J. Geophys. Res., 113, D13103, doi:10.1029/2008JD009944.

Jiang, D., and X. Lang (2010), Last Glacial Maximum East Asian monsoon: results of PMIP simulations, J. Climate, 23, 5030-5038.

Jiang, Y., X. Liu, X.-Q. Yang, and M. Wang (2013), A numerical study of the effect of different aerosol types on East Asian summer clouds and precipitation, Atmos. Environ., 70, 51-63, http://dx.doi.org/10.1016/j.atmosenv.2012.12.039.

Lamarque, J. F., et al. (2010), Historical (1850-2000) gridded anthropogenic and biomass burning emissions of reactive gases and aerosols: methodology and application, Atmos. Chem. Phys., 10, 7017-7039.

Lau, K.-M., et al. (2008), The joint Aerosol-Monsoon experiment: a new challenge for Monsoon climate research, Bull. Am. Meteorol. Soc., 89, 369-383.

Li, H., A. Dai, T. Zhou, and J. Lu (2010), Responses of East Asian summer monsoon to historical SST and atmospheric forcing during 1950-2000, Clim. Dyn., 34, 501-514, doi:10.1007/s00382-008-0482-7.

Li, Z., et al. (2011), East Asian studies of tropospheric aerosols and their impact on regional climate (EASTAIRC): An overview, J. Geophys. Res., 116, D00K34, doi:10.1029/2010JD015257. 
Liu, H. W., T. J. Zhou, Y. X. Zhu, et al. (2012a), The strengthening East Asia summer monsoon since the early 1990s, Chin. Sci. Bull., 57, 1553-1558, doi:10.1007/s11434-0124991-8.

Liu X., et al. (2012b), Towards a minimal representation of aerosol direct and indirect effects: model description and evaluation, Geosci. Model. Dev., 5, 709-735, doi:10.5194/gmd-4-709-2012.

Liu, X. D., L. B. Yan, P. Yang, Z.-Y. Yin, and G. R. North (2011a), Influence of Indian summer monsoon on aerosol loading in East Asia, J. Appl. Meteor. Climatol., 50, 523533, doi: http://dx.doi.org/10.1175/2010JAMC2414.1.

Liu, X. D., X. N. Xie, Z.-Y. Yin, C. H. Liu, and A. Gettelman (2011b), A modeling study of the effects of aerosols on clouds and precipitation over East Asia, Theor. Appl. Climatol., 106, 343-354, doi: 10.1007/s00704-011-0436-6.

Meehl, G. A., J. M. Arblaster, and W. D. Collins (2008), Effects of black carbon aerosols on the Indian monsoon, J. Climate, 21, 2869-2882, doi:10.1175/2007JCLI1777.1.

Menon, S., J. Hansen, L. Nazarenko, and Y. F. Luo (2002), Climate effects of black carbon aerosols in China and India, Science, 297, 2250-2253.

Morrison, H., and A. Gettelman (2008), A new two-moment bulk stratiform cloud microphysics scheme in the NCAR Community Atmosphere Model (CAM3), Part I: Description and numerical tests, J. Clim., 21, 3642-3659.

Nakajima T., and Coauthors (2007), Overview of the atmospheric brown cloud east Asian regional experiment 2005 and a study of the aerosol direct radiative forcing in east Asia, J. Geophys. Res., 112, D24S91, doi:10.1029/2007JD009009. 
Neale, R. B., et al. (2010), Description of the NCAR Community Atmosphere Model (CAM5.0), Tech. Rep. NCAR/TN-486+STR, Natl. Cent. for Atmos. Res., Boulder, Colo.

Ramanathan, V., P. J. Crutzen, J. T. Kiehl, and D. Rosenfeld (2001), Aerosols, climate, and the hydrological cycle, Science, 294, 2119-2124.

Rayner, N. A., D. E. Parker, E. B. Horton, C. K. Folland, L. V. Alexander, D. P. Rowell, E. C. Kent, and A. Kaplan (2003), Global analyses of sea surface temperature, sea ice, and night marine air temperature since the late nineteenth century, J. Geophys. Res., 108(D14), 4407, doi:10.1029/2002JD002670.

Song, F., T. Zhou, and Y. Qian (2014), Responses of East Asian summer monsoon to natural and anthropogenic forcings in the 17 latest CMIP5 models, Geophys. Res. Lett., 41, 596-603, doi:10.1002/2013GL058705.

Tao, W.-K., J.-P. Chen, Z. Li, C. Wang, and C. Zhang (2012), Impact of aerosols on convective clouds and precipitation, Rev. Geophys., 50, RG2001, DOI: 10.1029/2011RG000369.

Twomey, S. A. (1977), The influence of pollution on the shortwave albedo of clouds, $J$. Atmos. Sci., 34, 1149-1152.

Wang, B., and Q. Ding (2006), Changes in global monsoon precipitation over the past 56 years, Geophys. Res. Lett., 33, L06711, doi:10.1029/2005GL025347.

Wang, B., Z. Wu, J. Li, J. Liu, C.-P. Chang, Y. Ding, and G. Wu (2008), How to measure the strength of the East Asian summer monsoon, J. Climate, 21, 4449-4463.

Wang, H., (2001), The weakening of Asian monsoon circulation after the end of 1970s, Adv. Atmos. Sci., 18, 376-386, doi:10.1007/BF02919316. 
Wang, H. L., X. N. Xie, and X. D. Liu (2015), On the robustness of the weakening effect of anthropogenic aerosols on the East Asian summer monsoon with multimodel results, Adv. Meteor., 2015, 397395.

Wang, T. J., et al. (2015), The interactions between anthropogenic aerosols and the East Asian summer monsoon using RegCCMS, J. Geophys. Res. Atmos., 120, 5602-5621, doi:10.1002/2014JD022877.

Wu, R. G., J. L. Kinter, and B. P. Kirtman (2005), Discrepancy of interdecadal changes in the Asian region among the NCEP/NCAR reanalysis, objective analyses and observations, J. Climate, 18, 3048-3067.

Xiao, D., and J. Li (2007), Spatial and temporal characteristics of the decadal abrupt changes of global atmosphere-ocean system in the 1970s, J. Geophys. Res. Atmos., 112, D24S22, doi:10.1029/2007JD008956.

Xie, X. N., X. D. Liu, Y. Peng, Y. Wang, Z. G. Yue, and X. Z. Li (2013), Numerical simulation of clouds and precipitation depending on different relationships between aerosol and cloud droplet spectral dispersion, Tellus B, 65, 19054, http://dx.doi.org/10.3402/tellusb.v65i0.19054.

Yan, L. B., X. D. Liu, P. Yang, Z.-Y. Yin, and G. R. North (2011), Study of the impact of summer monsoon circulation on spatial distribution of aerosols in East Asia based on numerical simulations, J. Appl. Meteor. Climatol., 50, 2270-2282, doi: http://dx.doi.org/10.1175/2011JAMC-D-11-06.1.

Zhang, X. Y., Y. Q. Wang, T. Niu, X. C. Zhang, S. L. Gong, Y. M. Zhang, and J. Y. Sun (2012), Atmospheric aerosol compositions in China: spatial/temporal variability, chemical signature, regional haze distribution and comparisons with global aerosols, 
Atmos. Chem. Phys., 12, 779-799.

Zhou, T. J., D. Y. Gao, J. Li, and B. Li (2009), Detecting and understanding the multidecadal variability of the East Asian Summer Monsoon - Recent progress and state of affairs, Meteorol. Z., 18, 455-467.

Zhu, C., B. Wang, W. Qian, and B. Zhang (2012a), Recent weakening of northern East Asian summer monsoon: A possible response to global warming, Geophys. Res. Lett., 39(9), L09701, doi:10.1029/2012GL051155.

Zhu, J., H. Liao, and J. Li (2012b), Increases in aerosol concentrations over eastern China due to the decadal-scale weakening of the East Asian summer monsoon, Geophys. Res. Lett., 39, L09809, doi:10.1029/2012GL051428. 
Table 1. Description of the numerical experiments in our study

\begin{tabular}{cccc}
\hline Experiment & simulated time & SST and GHGs & aerosol emissions \\
\hline CTL & $1950-2000$ & historical SST and GHGs & AR5 1850-2005 \\
PD & $1950-2000$ & historical SST and GHGs & Fixed AR5 2000 \\
PI & $1950-2000$ & historical SST and GHGs & Fixed AR5 1850 \\
\hline
\end{tabular}


Summer AOD, total anthropogenic aerosol column burden $\left(\mathrm{AB}, \mathrm{mg} \mathrm{m}^{-2}\right)$ and sulfate, BC and POM column burden for PD and PI, and their differences (PD-PI), based on spatially averaged values for eastern China and North China in the strong (P1) and weak (P2)

\begin{tabular}{ccccrcc}
\hline & $\mathrm{PD}(\mathrm{P} 1)$ & $\mathrm{PI}(\mathrm{P} 1)$ & Diff(P1) & $\mathrm{PD}(\mathrm{P} 2)$ & $\mathrm{PI}(\mathrm{P} 2)$ & Diff(P2) \\
\hline AOD (eastern China) & 0.223 & 0.123 & 0.100 & 0.234 & 0.121 & 0.113 \\
$\mathrm{AB}$ (Sulfate+BC+POM) (eastern China) & 17.47 & 1.97 & 15.50 & 18.58 & 1.99 & 16.59 \\
AB (Sulfate) (eastern China) & 12.81 & 0.79 & 12.02 & 13.83 & 0.81 & 13.02 \\
AB (BC) (eastern China) & 1.07 & 0.14 & 0.93 & 1.08 & 0.14 & 0.94 \\
AB (POM) (eastern China) & 3.59 & 1.04 & 2.55 & 3.67 & 1.04 & 2.63 \\
AOD (North China) & 0.299 & 0.183 & 0.116 & 0.315 & 0.178 & 0.137 \\
AB (Sulfate+BC+POM) (North China) & 20.83 & 2.47 & 18.36 & 22.37 & 2.47 & 19.90 \\
AB (Sulfate) (North China) & 15.24 & 0.84 & 14.40 & 16.58 & 0.85 & 15.73 \\
AB (BC) (North China) & 1.24 & 0.18 & 1.06 & 1.27 & 0.18 & 1.09 \\
AB (POM) (North China) & 4.35 & 1.45 & 2.90 & 4.52 & 1.44 & 3.08 \\
\hline
\end{tabular}


Table 3. Large-scale EASM intensity (V) and the total precipitation (Prect) in summer over North China for PD, PI, their difference (PD-PI), and their percentage change ((PD-PI)/PI $\times 100 \%)$ in the strong $(\mathrm{P} 1)$ and weak $(\mathrm{P} 2)$ EASM stages

\begin{tabular}{ccccr}
\hline & $\mathrm{V}\left(\mathrm{m} \mathrm{s}^{-1}\right)$ & & Prect $\left(\mathrm{mm} \mathrm{day}^{-1}\right)$ & $\mathrm{P} 2$ \\
\hline $\mathrm{P} 1$ & $\mathrm{P} 2$ & $\mathrm{P} 1$ & 4.97 \\
PD & 3.66 & 3.42 & 5.23 & 5.59 \\
PI & 3.83 & 3.79 & 5.13 & -0.62 \\
Change & -0.17 & -0.37 & 0.10 & $-11.1 \%$ \\
\hline
\end{tabular}


Table 4. Descriptive statistics of the $850 \mathrm{hPa}$ water vapor flux and flux convergence, $850 \mathrm{hPa}$ specific humidity, total precipitation water, and $850 \mathrm{hPa}$ vertical velocity in summer for $\mathrm{PD}, \mathrm{PI}$ and their difference (PD-PI), based on spatially averaged values for North China in the strong (P1) and weak (P2) EASM stages

\begin{tabular}{ccccrrc}
\hline & $\mathrm{PD}(\mathrm{P} 1)$ & $\mathrm{PI}(\mathrm{P} 1)$ & Diff(P1) & $\mathrm{PD}(\mathrm{P} 2)$ & $\mathrm{PI}(\mathrm{P} 2)$ & Diff(P2) \\
\hline Water vapor flux $\left(\mathrm{g}(\mathrm{hPa} \mathrm{m} \mathrm{s})^{-1}\right)$ & 36.96 & 37.71 & -0.75 & 35.41 & 38.59 & -3.18 \\
Water flux convergence $\left.\left(10^{-5} \mathrm{~g} \mathrm{(hPa} \mathrm{m}^{2} \mathrm{~s}\right)^{-1}\right)$ & -1.40 & -1.41 & 0.01 & -1.20 & -1.62 & 0.42 \\
Specific humidity $\left(\mathrm{g} \mathrm{kg}^{-1}\right)$ & 11.68 & 11.64 & 0.04 & 11.64 & 12.01 & -0.37 \\
Precipitation water $\left(\mathrm{kg} \mathrm{m}^{-2}\right)$ & 34.96 & 34.65 & 0.31 & 34.73 & 35.87 & -1.13 \\
Vertical velocity $\left(0.01 \times \mathrm{Pa} \mathrm{s}^{-1}\right)$ & -2.02 & -1.83 & -0.19 & -1.65 & -1.97 & 0.33 \\
\hline
\end{tabular}


Table 5. Column cloud droplet number concentration (CDNUMC), liquid water path (LWP), cloud droplet effective radius for $850 \mathrm{hPa}$ (Re) and low cloud cover (CLDLOW) in summer for PD, PI and their differences (PD-PI) over eastern China in the strong (P1) and weak (P2)

\begin{tabular}{ccccrrc}
\hline & $\mathrm{PD}(\mathrm{P} 1)$ & $\mathrm{PI}(\mathrm{P} 1)$ & Diff(P1) & $\mathrm{PD}(\mathrm{P} 2)$ & $\mathrm{PI}(\mathrm{P} 2)$ & Diff(P2) \\
\hline CDNUMC $\left(10^{6} \mathrm{~cm}^{-2}\right)$ & 4.20 & 1.42 & 2.78 & 4.04 & 1.42 & 2.63 \\
LWP $\left(\mathrm{g} \mathrm{m}^{-2}\right)$ & 109.47 & 86.47 & 23.00 & 106.77 & 88.02 & 18.75 \\
Re $(\mu \mathrm{m})$ & 8.28 & 9.50 & -1.23 & 8.27 & 9.56 & -1.29 \\
CLDLOW $(\%)$ & 31.94 & 30.42 & 1.52 & 31.29 & 30.75 & 0.54 \\
\hline
\end{tabular}


Table 6. Surface temperature (TS), sea-level pressure (SLP), shortwave (SW) and longwave (LW) radiative fluxes, as well as the total radiative fluxes (SW+LW) for clear-sky and cloudy-sky conditions at the surface in summer for PD, PI and their difference (PD-PI) over eastern China in the strong (P1) and weak (P2) EASM stages

\begin{tabular}{|c|c|c|c|c|c|c|}
\hline & $\mathrm{PD}(\mathrm{P} 1)$ & $\mathrm{PI}(\mathrm{P} 1)$ & Diff(P1) & $\mathrm{PD}(\mathrm{P} 2)$ & $\mathrm{PI}(\mathrm{P} 2)$ & Diff(P2) \\
\hline $\mathrm{TS}\left({ }^{\circ} \mathrm{C}\right)$ & 25.35 & 25.74 & -0.39 & 25.74 & 26.18 & -0.44 \\
\hline $\mathrm{SLP}(\mathrm{hPa})$ & 1005.28 & 1005.12 & 0.16 & 1004.99 & 1004.7 & 0.30 \\
\hline SW (Surface & 280.62 & 288.86 & -8.23 & 278.68 & 287.56 & -8.88 \\
\hline LW & -63.12 & -64.70 & 1.57 & -62.38 & -62.98 & 0.60 \\
\hline Clear-sky SW+LW (Surface, $\mathrm{W} \mathrm{m}^{-2}$ ) & 217.50 & 224.16 & -6.66 & 216.30 & 224.58 & -8.28 \\
\hline Cloudy-sky SW (Surface, W m-2) & -98.69 & -91.20 & -7.49 & -96.17 & -91.27 & -4.90 \\
\hline Cloudy-sky LW (Surface, $\mathrm{W} \mathrm{m}^{-2}$ ) & 18.55 & 17.49 & 1.06 & 17.50 & 16.97 & 0.53 \\
\hline Cloudy-sky SW+LW (Surface, $\mathrm{W} \mathrm{m}^{-2}$ ) & -80.15 & -73.71 & -6.44 & -78.66 & -74.30 & -4.36 \\
\hline
\end{tabular}


Table 7. Clear-sky and cloudy-sky shortwave (SW), longwave (LW) and total radiative fluxes $(\mathrm{SW}+\mathrm{LW})$ at the top of atmosphere $(\mathrm{TOA})$ in summer for PD, PI and their difference (PD-PI) for eastern China in the strong (P1) and weak (P2) EASM stages

\begin{tabular}{|c|c|c|c|c|c|c|}
\hline & $\mathrm{PD}(\mathrm{P} 1)$ & $\mathrm{PI}(\mathrm{P} 1)$ & Diff(P1) & $\mathrm{PD}(\mathrm{P} 2)$ & $\mathrm{PI}(\mathrm{P} 2)$ & Diff(P2) \\
\hline Clear-sky SW (TOA, W m ${ }^{-2}$ ) & 389.44 & 391.34 & -1.91 & 388.58 & 390.94 & -2.36 \\
\hline Clear-sky LW (TOA, W m ${ }^{-2}$ ) & -277.16 & -278.25 & 1.09 & 276.58 & 277.38 & 0.80 \\
\hline Clear-sky SW+LW (TOA, W m ${ }^{-2}$ ) & 112.28 & 113.09 & -0.82 & 112.00 & 113.57 & -1.56 \\
\hline Cloudy-sky SW (TOA, W m²) & -92.83 & -84.94 & -7.89 & -90.53 & -85.09 & -5.44 \\
\hline Cloudy-sky LW (TOA, W m ${ }^{-2}$ ) & 43.61 & 39.88 & 3.73 & 42.47 & 39.85 & 2.62 \\
\hline Cloudy-sky SW+LW (TOA, W m $\left.{ }^{-2}\right)$ & -49.22 & -45.06 & -4.16 & -48.06 & -45.24 & -2.82 \\
\hline
\end{tabular}


Table 8. Aerosol direct radiative forcing (ADF) and indirect radiative forcing (AIF) including shortwave (SW), longwave (LW) and total radiative fluxes $(\mathrm{SW}+\mathrm{LW})$ in summer at the surface and at the top of atmosphere (TOA) over eastern China in the strong (P1) and weak (P2) EASM

\begin{tabular}{|c|c|c|c|c|}
\hline & $\mathrm{ADF}(\mathrm{P} 1)$ & $\mathrm{AIF}(\mathrm{P} 1)$ & $\mathrm{ADF}(\mathrm{P} 2)$ & $\mathrm{AIF}(\mathrm{P} 2)$ \\
\hline SW (Surface, $\mathrm{W} \mathrm{m}^{-2}$ ) & -8.23 & -7.49 & -8.88 & -4.90 \\
\hline LW (Surface, $W \mathrm{~m}^{-2}$ ) & 1.57 & 1.06 & 0.60 & 0.53 \\
\hline $\mathrm{SW}+\mathrm{LW}$ (Surface, $\mathrm{W} \mathrm{m}^{-2}$ ) & -6.66 & -6.44 & -8.28 & -4.36 \\
\hline $\mathrm{SW}\left(\mathrm{TOA}, \mathrm{W} \mathrm{m}^{-2}\right)$ & -1.91 & -7.89 & -2.36 & -5.44 \\
\hline $\mathrm{LW}\left(\mathrm{TOA}, \mathrm{W} \mathrm{m}^{-2}\right)$ & 1.09 & 3.73 & 0.80 & 2.62 \\
\hline $\mathrm{SW}+\mathrm{LW}\left(\mathrm{TOA}, \mathrm{W} \mathrm{m}^{-2}\right)$ & -0.82 & -4.16 & -1.56 & -2.82 \\
\hline
\end{tabular}


Table 9. Sensitivity, i.e., (PD-PI)/ $\triangle \mathrm{AOD}$, of the changes between PD and PI to anthropogenic $\mathrm{AOD}$, including $\mathrm{ADF}, \mathrm{AIF}$, and the aerosol total radiative forcing (ADF+AIF) at the surface and at the top of atmosphere (TOA), the surface temperature, the sea-level pressure over eastern China, the large-scale EASM intensity (V) and the total precipitation (PRECT) in summer over North China in the strong (P1) and weak (P2) EASM stages

\begin{tabular}{|c|c|c|}
\hline Sensitivity & P1 & P2 \\
\hline ADF (Surface, $\mathrm{W} \mathrm{m}^{-2}$ ) & -66.6 & -73.3 \\
\hline $\mathrm{ADF}\left(\mathrm{TOA}, \mathrm{W} \mathrm{m}^{-2}\right)$ & -8.2 & -13.8 \\
\hline AIF (Surface, $\mathrm{W} \mathrm{m}^{-2}$ ) & -64.4 & -38.6 \\
\hline $\operatorname{AIF}\left(\right.$ TOA, $\mathrm{W} \mathrm{m}^{-2}$ ) & -41.6 & -25.0 \\
\hline $\mathrm{ADF}+\mathrm{AIF}$ (Surface, $\mathrm{W} \mathrm{m}^{-2}$ ) & -131.0 & -111.9 \\
\hline $\mathrm{ADF}+\mathrm{AIF}\left(\mathrm{TOA}, \mathrm{W} \mathrm{m} \mathrm{m}^{-2}\right)$ & -49.8 & -38.8 \\
\hline TS ( & -3.9 & -3.9 \\
\hline SLP & 1.6 & 2.7 \\
\hline $\mathrm{V}\left(\mathrm{m} \mathrm{s}^{-1}\right)$ & -1.7 & -3.3 \\
\hline $\operatorname{PRECT}\left(\mathrm{mm} \mathrm{day}^{-1}\right)$ & 1.0 & -5.5 \\
\hline
\end{tabular}



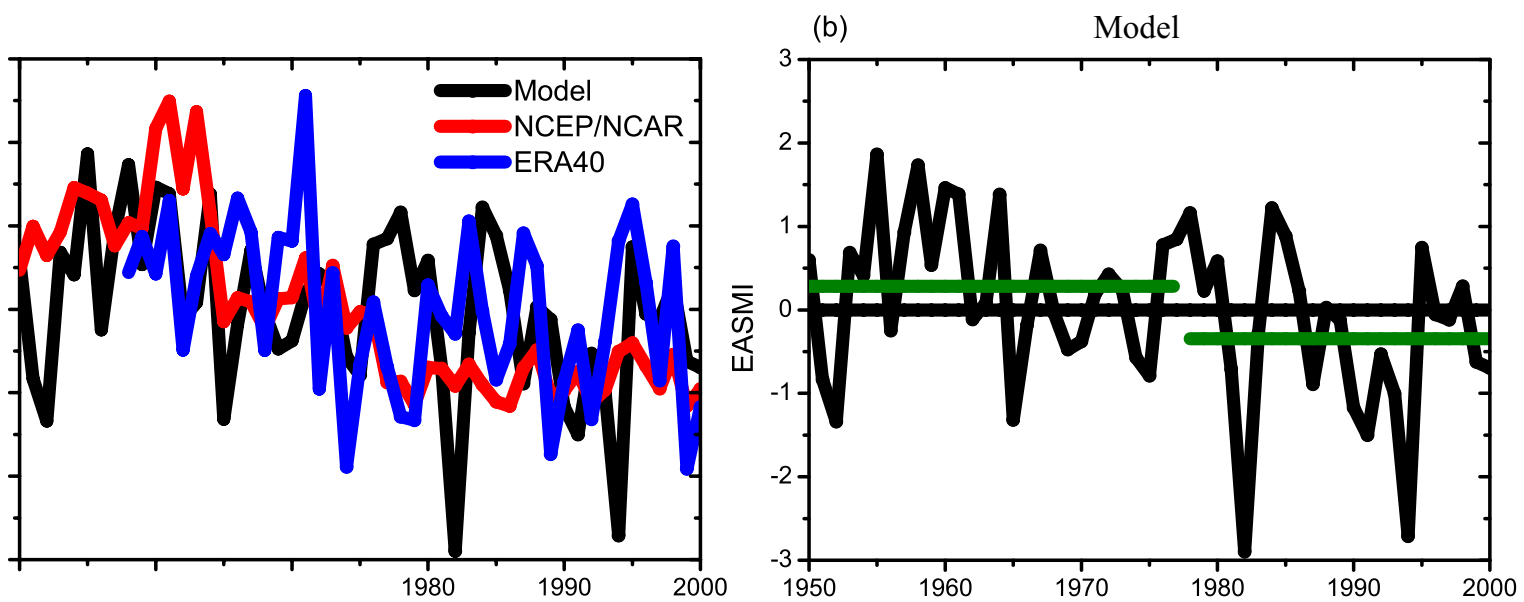

NCEP/NCAR

(d)

ERA40
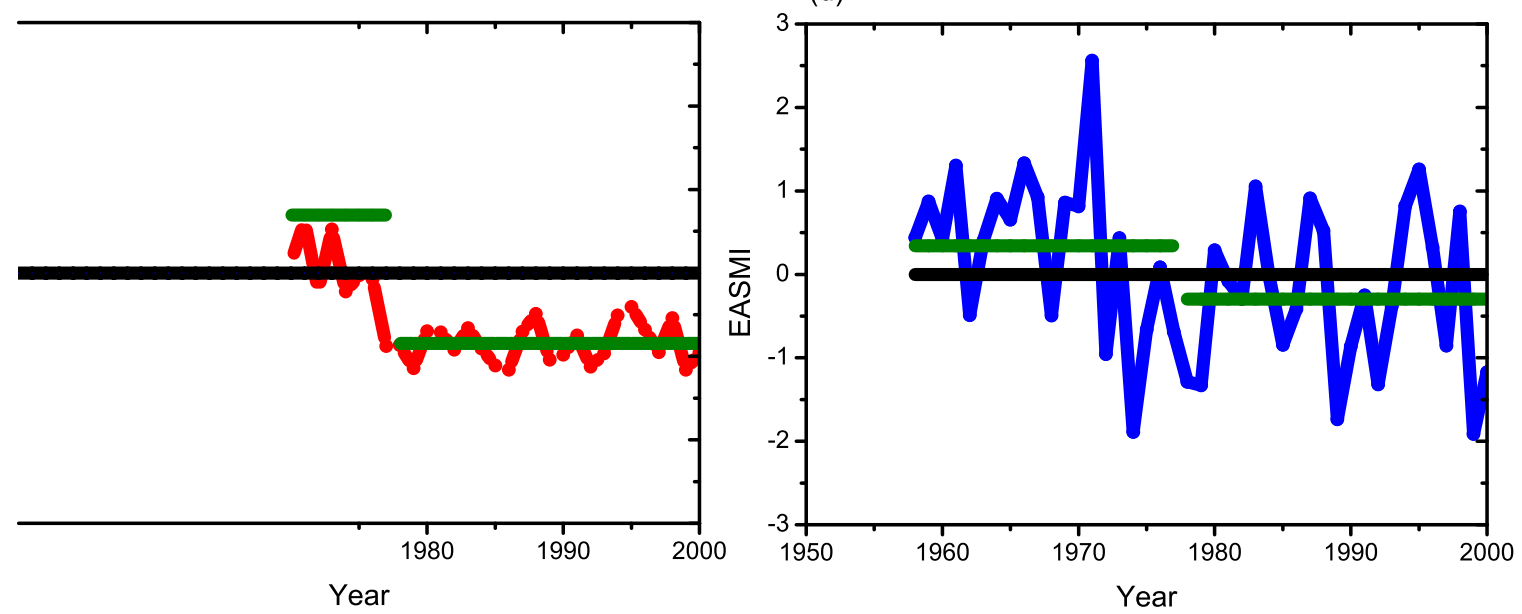

Time series of the normalized EASM index (EASMI) during 1950-2000 for the model, the NCEP/NCAR and ERA-40 reanalyses. The green lines (b, $c$ and d) are the average value of the EASMI at 1950-1977 (strong) and 1978-2000 (weak) stages. 
(a) $850 \mathrm{hPa}$ wind for Model

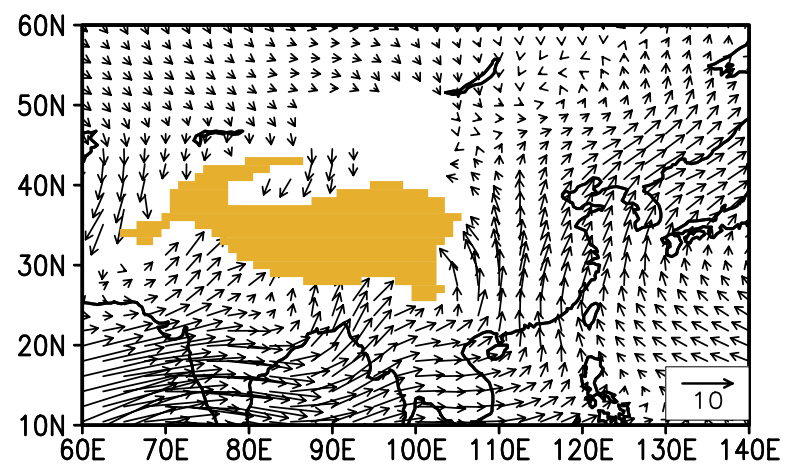

(c) $850 \mathrm{hPa}$ wind for NCEP/NCAR

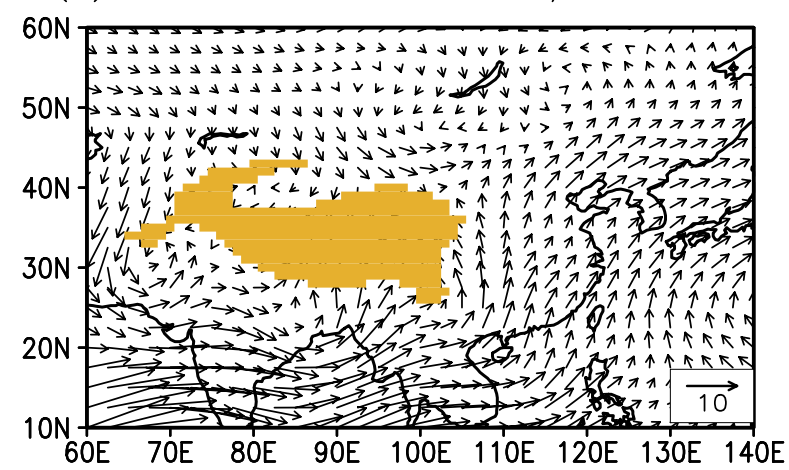

(e) $850 \mathrm{hPa}$ wind for ERA40

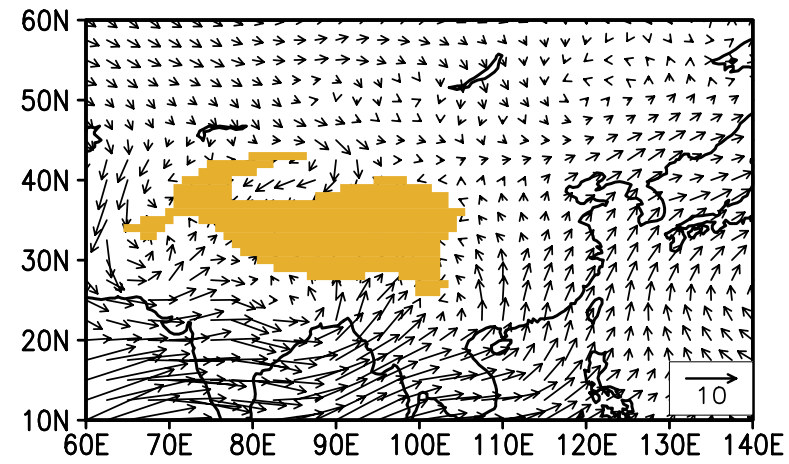

(b) Diff in $850 \mathrm{hPa}$ wind for Model

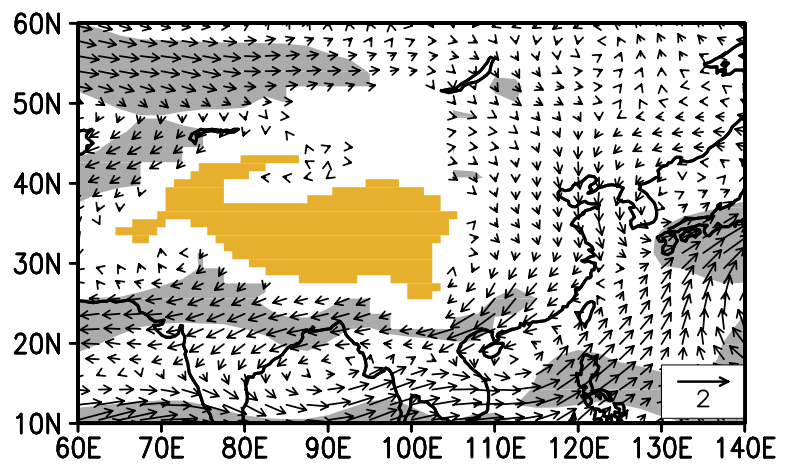

(d) Diff in $850 \mathrm{hPa}$ wind for NCEP/NCAR

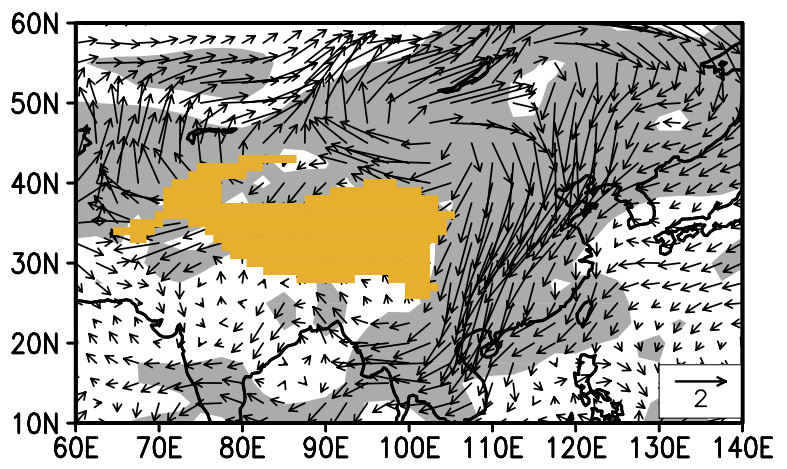

(f) Diff in $850 \mathrm{hPa}$ wind for ERA40

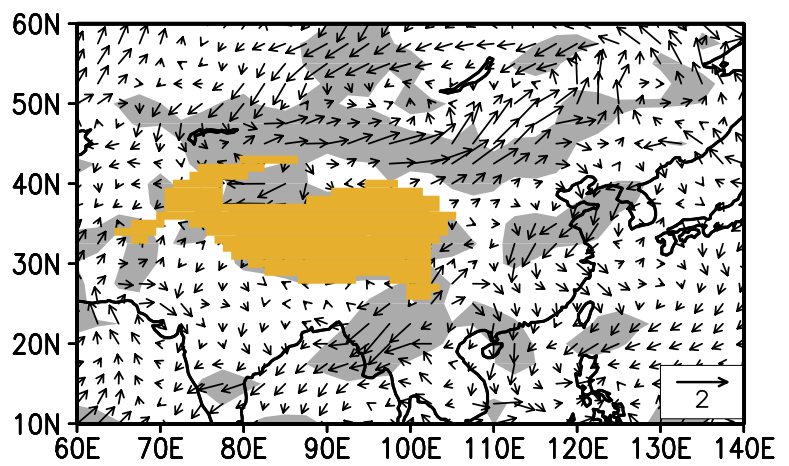

Figure 2. Summer mean $850 \mathrm{hPa}$ winds (1950-2000) and the difference between the weak (P2)

and strong (P1) EASM stages from (a, b) the model, (c, d) the NCEP/NCAR reanalysis, and $(\mathrm{e}, \mathrm{f})$ the ERA-40 reanalysis. The grey shaded area represents the grid points where the changes pass the two-tailed t-test at the $5 \%$ significance level, and the yellow shaded area indicates the plateau above 2,000 m. 
(a) Diff in AOD for $P 1$

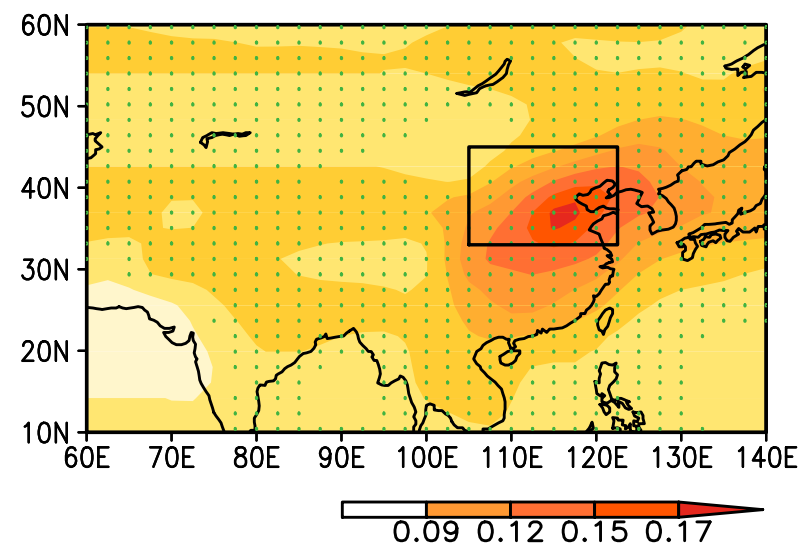

(b) Diff in AOD for $P 2$

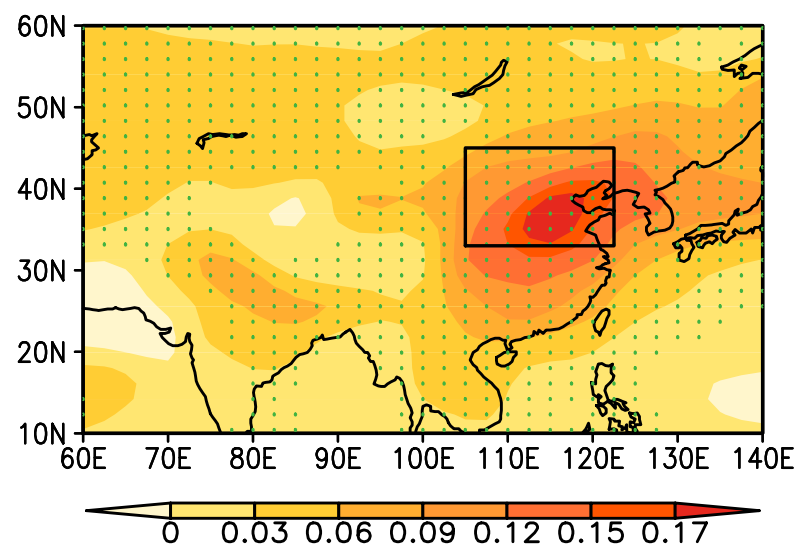

Figure 3. Differences in summer AOD between PD and PI for the (a) strong and (b) weak EASM stages labeled P1 and P2, respectively. The dots represent the grid points where the changes pass the two-tailed t-test at the 5\% significance level. The box indicates the North China region defined in this study $(33-45 \mathrm{~N}, 105-122.5 \mathrm{E})$. 


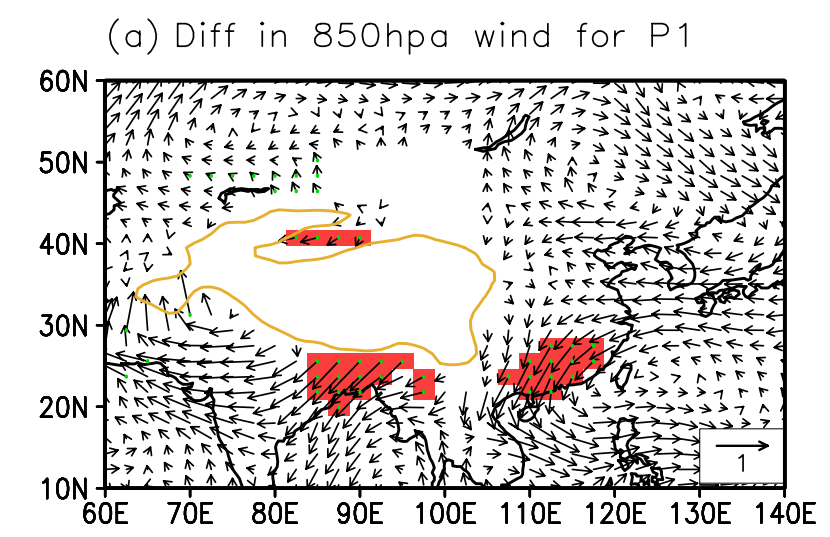

(b) Diff in 850hpa wind for P2

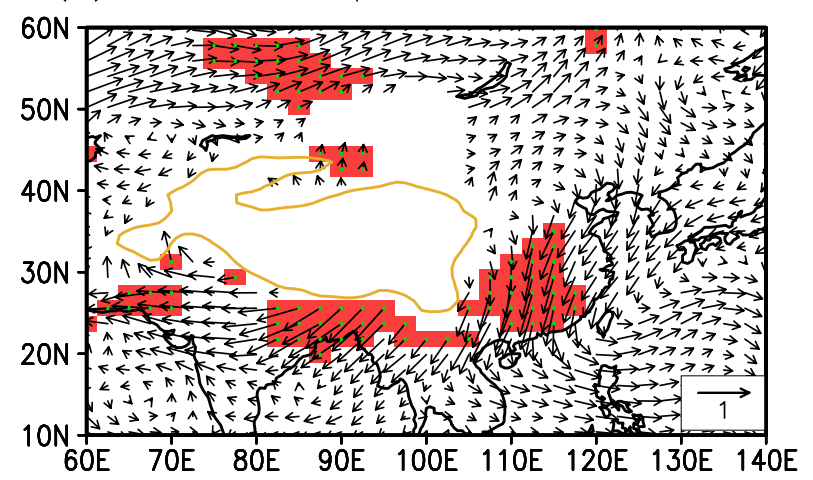

Figure 4. Differences in the summer $850 \mathrm{hPa}$ wind field $\left(\mathrm{m} \mathrm{s}^{-1}\right)$ between $\mathrm{PD}$ and PI for the

(a) strong and (b) weak EASM stages labeled P1 and P2, respectively. The red shaded regions with green dots represent the grid points where the changes pass the two-tailed t-test at the $5 \%$ significance level. The yellow contoured area indicates the plateau above 2,000 m. 
(a) Diff in surface temperature for $\mathrm{P} 1$

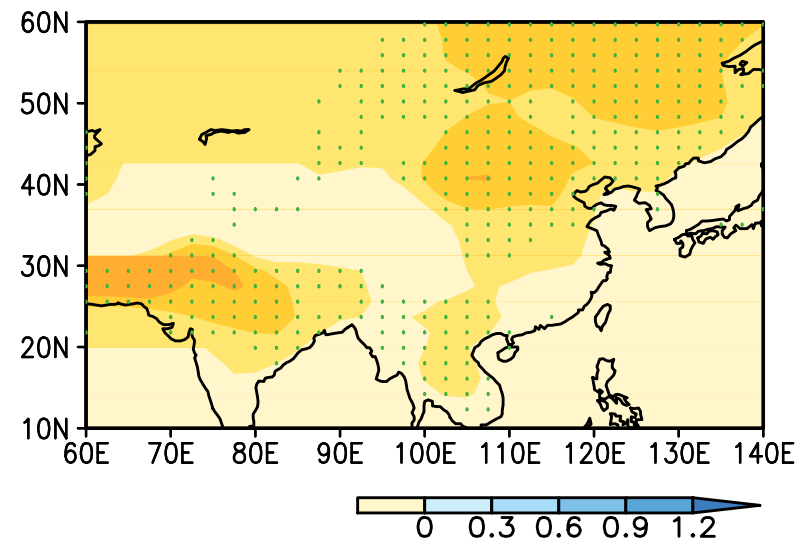

(c) Diff in sea level pressure for P1

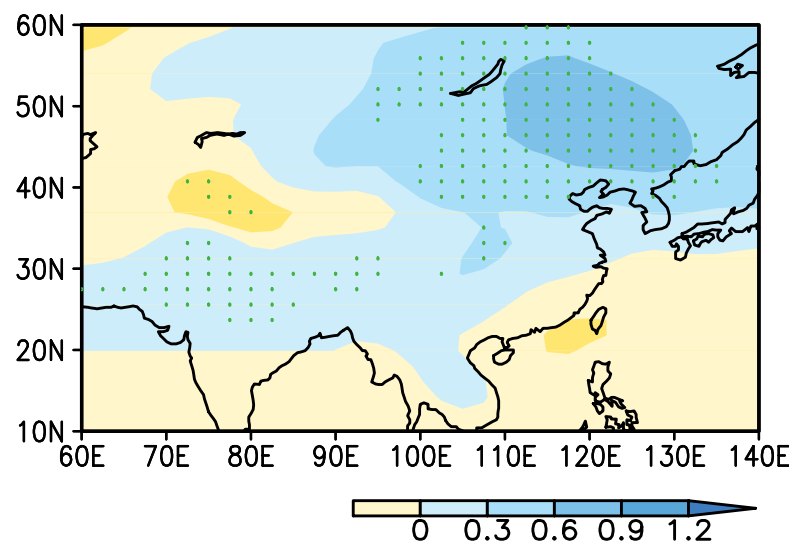

(b) Diff in surface temperature for P2

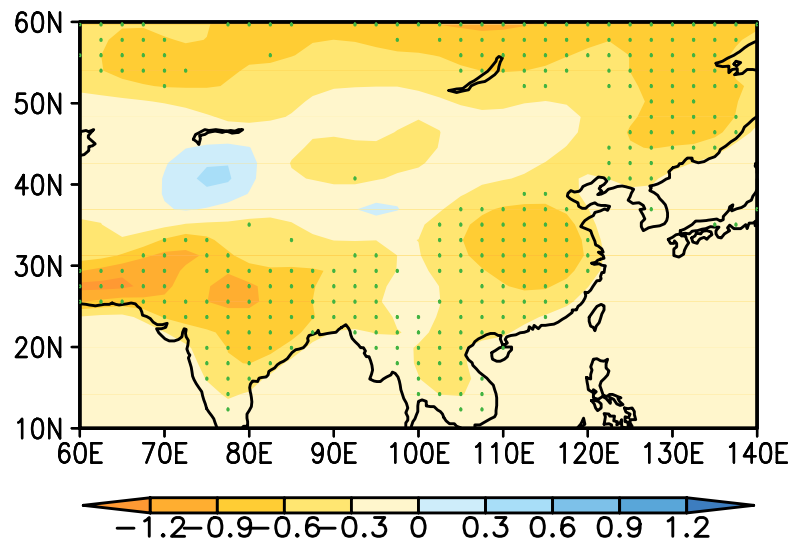

(d) Diff in sea level pressure for P2

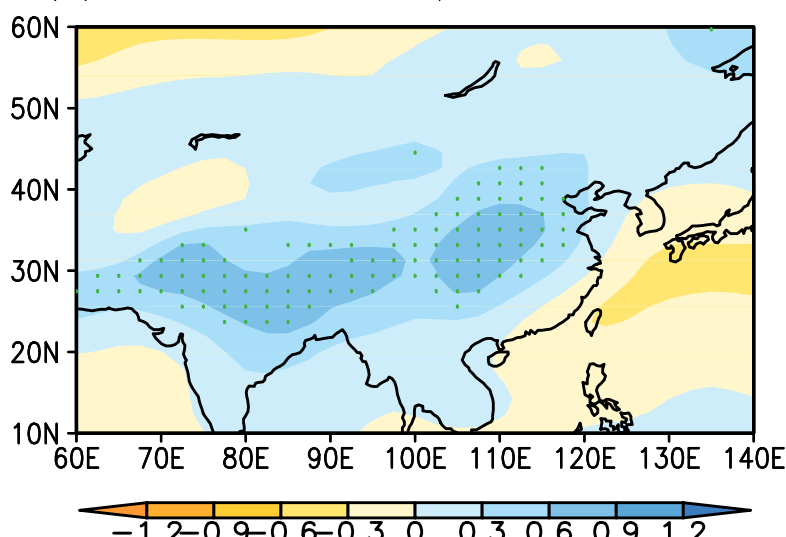

Figure 5. Differences in the surface temperature $\left({ }^{\circ} \mathrm{C}\right)$ and sea-level pressure $(\mathrm{hPa})$ in summer between PD and PI for the (a) strong and (b) weak EASM stages labeled P1 and P2, respectively. The dots represent the grid points where the changes pass the two-tailed t-test at the $5 \%$ 
(a) Diff in surface precipitation for P1

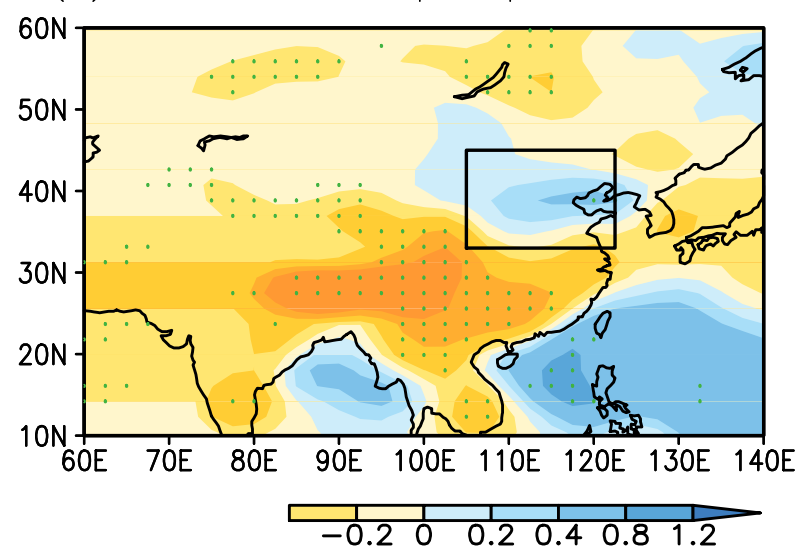

(b) Diff in surface precipitation for P2

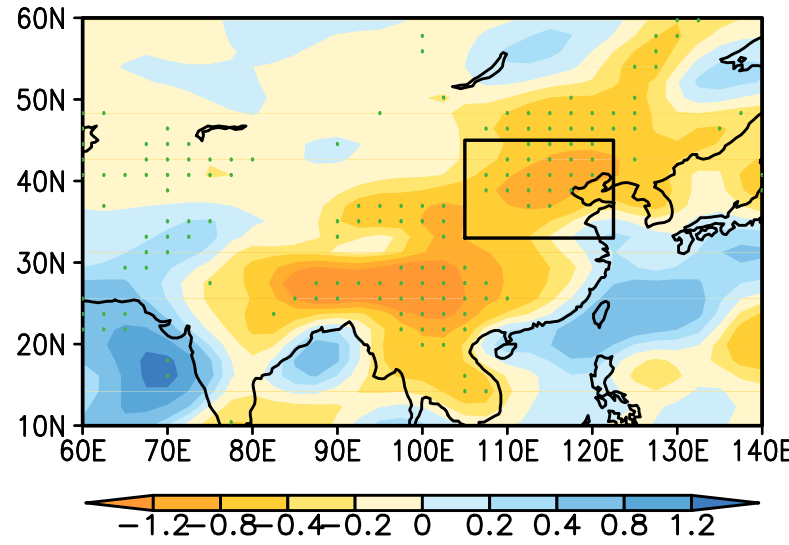

Differences in summer surface precipitation (shading; $\mathrm{mm} \mathrm{day}^{-1}$ ) between PD and PI for the (a) strong and (b) weak EASM stages labeled P1 and P2, respectively. The dots represent the grid points where the changes pass the two-tailed t-test at the $5 \%$ significance level. The box indicates the North China region defined in this study. 
(a) Diff in water vapor flux for P1

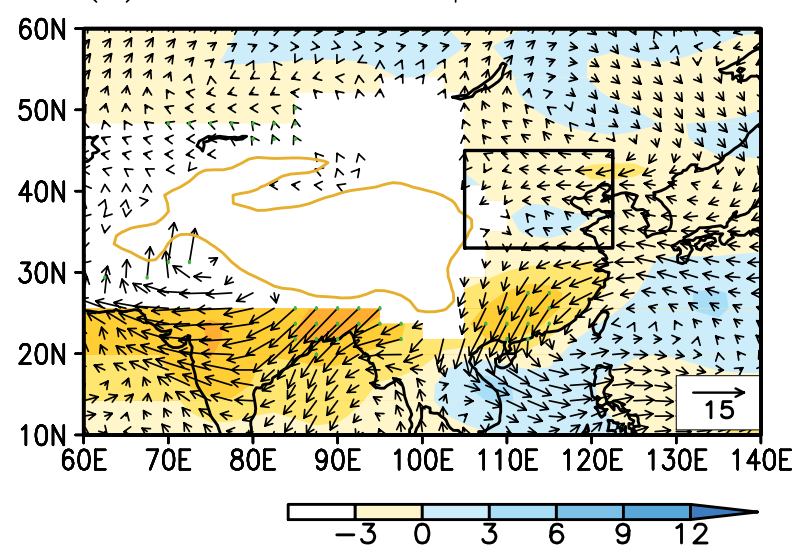

(c) Diff in specific humidity for P1

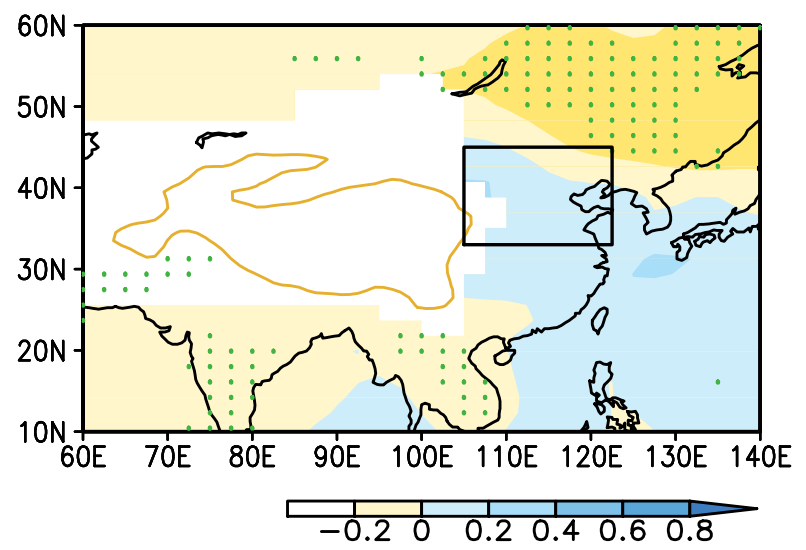

(b) Diff in water vapor flux for P2

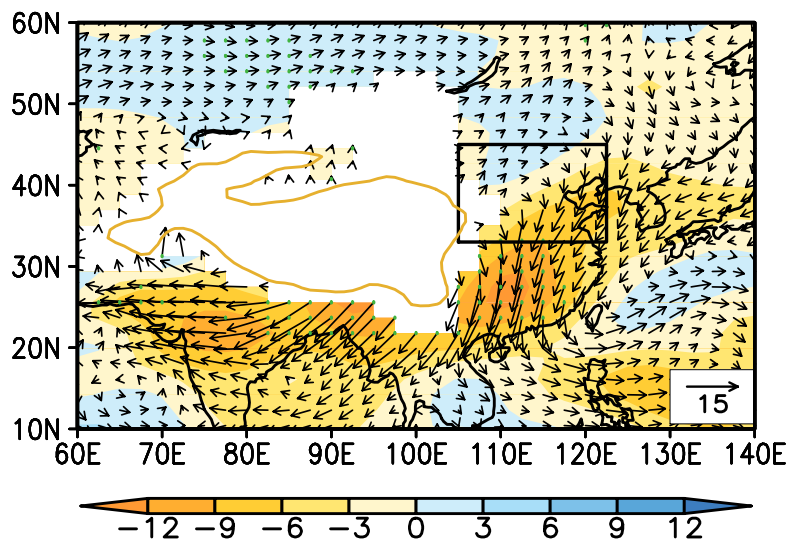

(d) Diff in specific humidity for P2

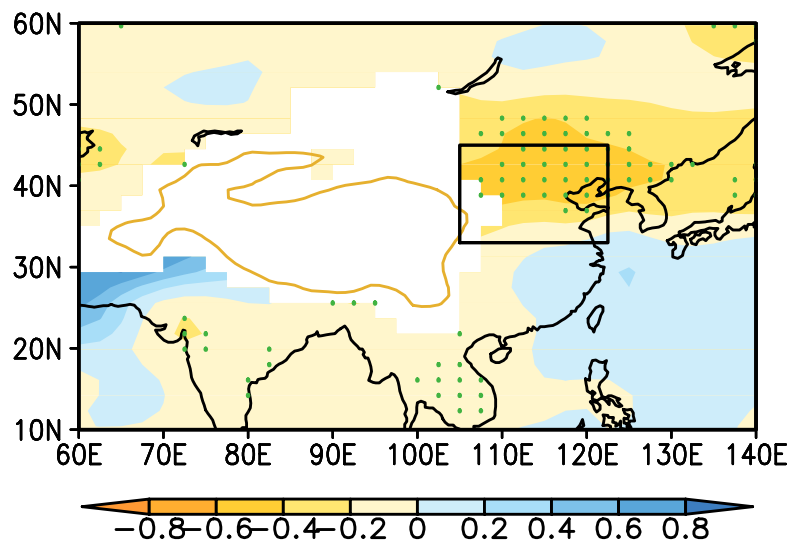

Figure 7. Differences in the summer water vapor transport $\left(\mathrm{g}(\mathrm{hPa} \mathrm{m} \mathrm{s})^{-1}\right)$ at $850 \mathrm{hPa}$ between PD and PI for the (a) strong and (b) weak EASM stages labeled P1 and P2, respectively. Shading: absolute value of water vapor transport at each grid. Differences in the summer specific humidity $\left(\mathrm{g} \mathrm{kg}^{-1}\right)$ at $850 \mathrm{hPa}$ between PD and PI for the (c) strong and (d) weak EASM stages. The dots represent the grid points where the changes pass the two-tailed t-test at the $5 \%$ significance level. The box indicates the North China region defined in this study and the yellow contoured area indicates the plateau above $2,000 \mathrm{~m}$. 
(a) Diff in vertical velocity for P1

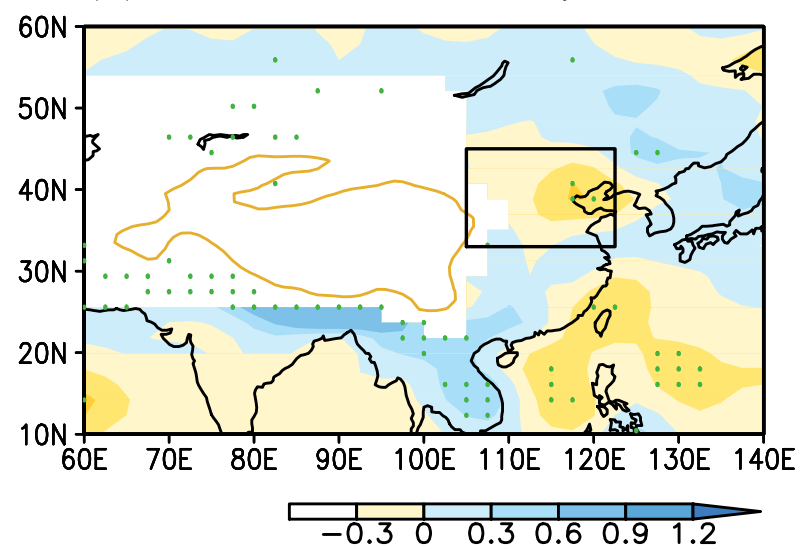

(b) Diff in vertical velocity for P2

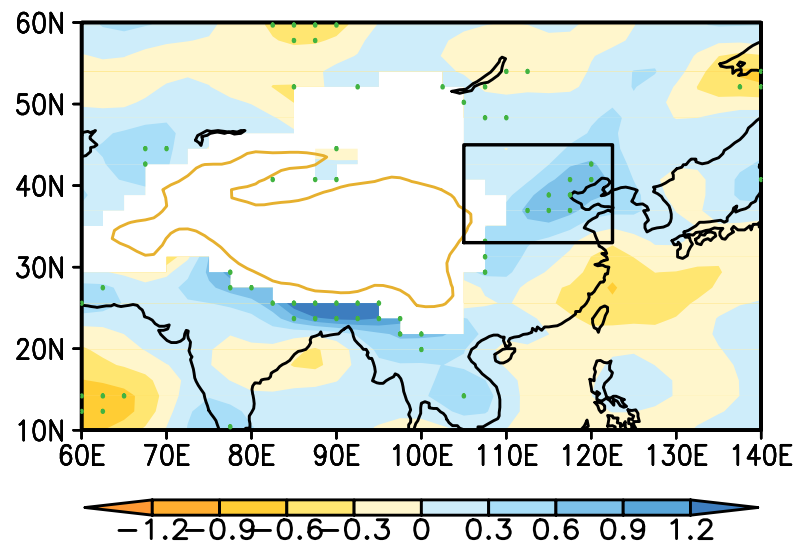

Differences in the summer vertical velocity $\left(0.01 \times \mathrm{Pa} \mathrm{s}^{-1}\right)$ at the $850 \mathrm{hPa}$ level

between PD and PI for the (a) strong and (b) weak EASM stages labeled P1 and P2, respectively. The dots represent the grid points where the changes pass the two-tailed t-test at the $5 \%$ significance level. The box indicates the North China region defined in this study and the yellow contoured area indicates the plateau above 2,000 m. 
(a) ADF +AIF in surface for P1

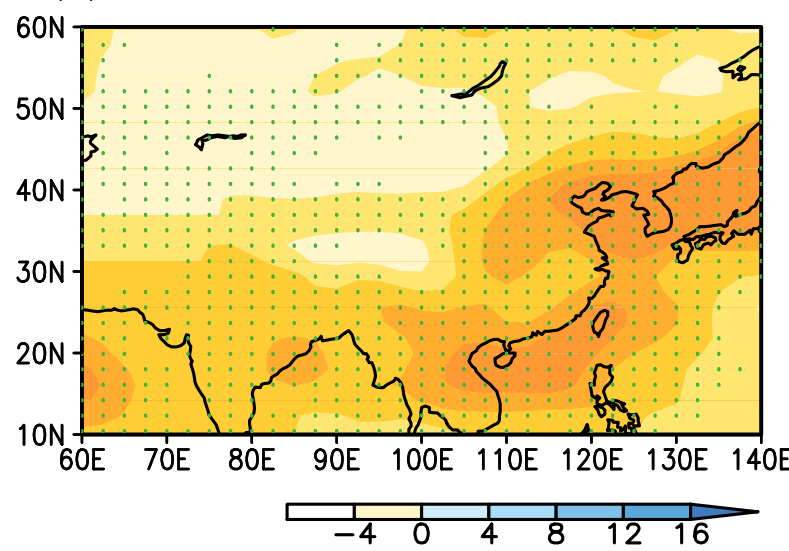

(c) ADF + AIF in TOA for P1

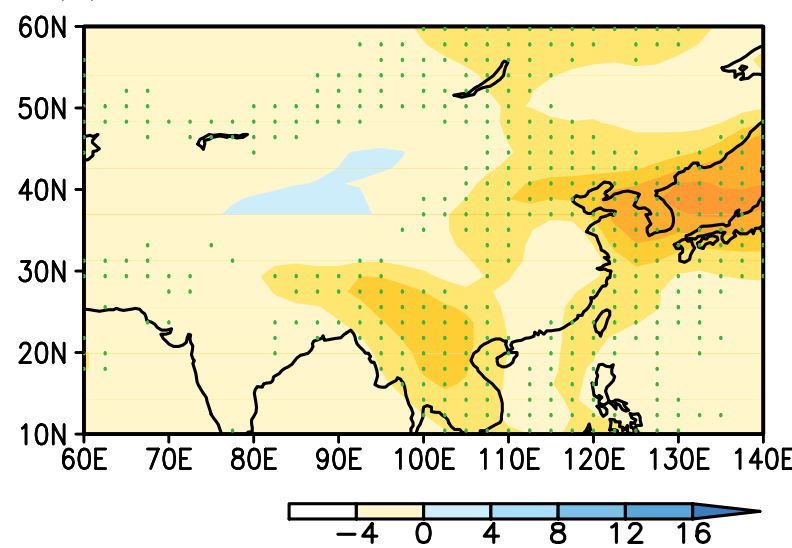

(b) ADF+AIF in surface for P2

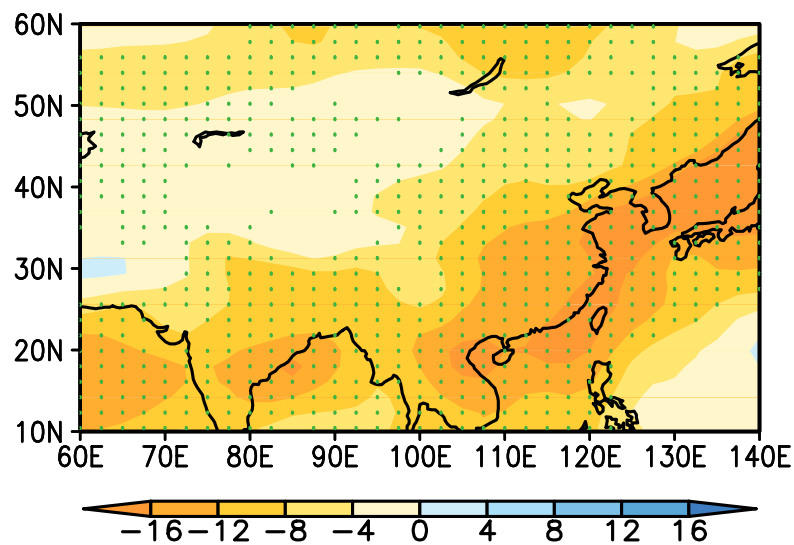

(d) ADF + AlF in TOA for P2

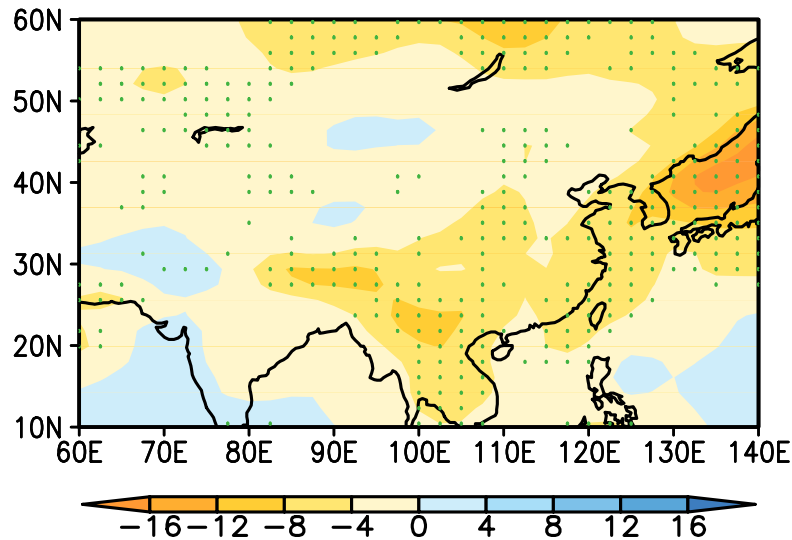

Figure 9. Differences in the surface and TOA aerosol total radiative flux (ADF+AIF, $\mathrm{W} \mathrm{m}^{-2}$ ) in summer for the (a, b) strong (P1) and (c, d) weak (P2) EASM stages. The dots represent the grid points where the changes pass the two-tailed t-test at the $5 \%$ significance level. 


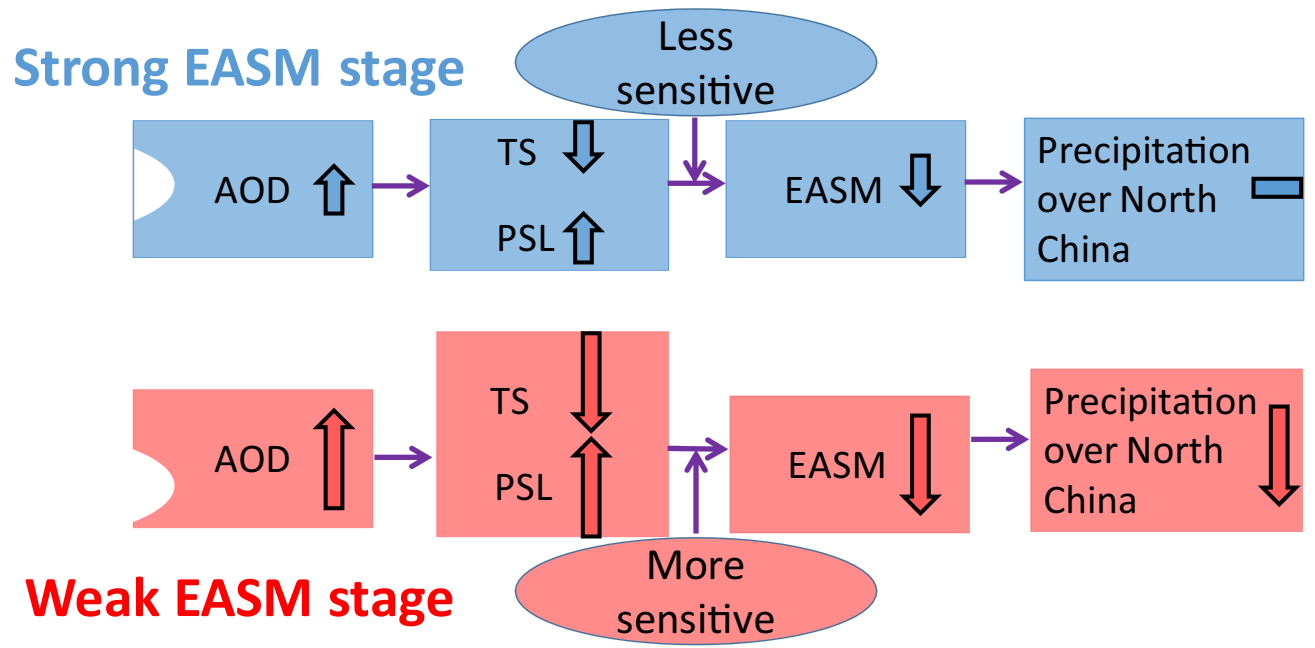

Figure 10. Schematic diagram showing the distinct effects of anthropogenic aerosols on the EASM and the associated summer precipitation over North China between the multi-decadal strong and weak monsoon stages. The up and down arrows denote an increase and a decrease, respectively, in the corresponding properties. The arrow length qualitatively indicates the extent of aerosol-induced changes. The bar indicates a statistically insignificant change in precipitation. 